Host-targeted Pan-respiratory Antiviral Therapeutics

\title{
From COVID-19 to the Common Cold: Novel Host-Targeted, Pan-Respiratory Antiviral Small Molecule Therapeutics
}

Suganya Selvarajah ${ }^{a}$, Anuradha F. Lingappa ${ }^{a}$, Maya Michona ${ }^{a}$ Li Du ${ }^{b}$, Fred Deiter ${ }^{c}$ Shao Feng $\mathrm{Yu}^{\mathrm{a}}$, Amanda Macieik$^{\mathrm{a}}$, Suguna Mallesh ${ }^{\mathrm{a}}$, Umesh Appaiah ${ }^{\mathrm{a}}$, Jackelyn Crabtree $^{\mathrm{d}}$, Kiel Copeland $^{\mathrm{a}}$, Andreas Müller-Schiffmann ${ }^{\mathrm{e}}$ Lisa Müller ${ }^{f}$, Philipp Niklas Ostermann ${ }^{f}$, Marcel Andrée $^{f}$, Ortwin Adams $^{f}$, Heiner Schaal ${ }^{f}$, Robert J. Hogan ${ }^{d}$, Ralph A. Tripp ${ }^{d}$, Sanjeev K. Anand ${ }^{g}$, Thomas W. Campi $^{g}$, Michael J. Ford ${ }^{\mathrm{h}}$, Jonathan C. Reedi, Jim Lin ${ }^{\mathrm{a}}$, Olayemi Akintunde ${ }^{\mathrm{a}}$, Christine Nichols ${ }^{\mathrm{a}}$, Emma Petrouski ${ }^{a}$, A. Raquel Moreira ${ }^{a}$, I-ting Jiang ${ }^{a}$, Nicholas DeYarman ${ }^{a}$, Sean Broce ${ }^{a}$, Ian Brown $^{a}$, Sharon Lau ${ }^{a}$, Ilana Segal ${ }^{a}$, Danielle Goldsmith ${ }^{a}$, Shi Hong ${ }^{a}$, Vinod Asundi ${ }^{a}$, Erica M. Briggs $^{a}$, Ngwe Sin Phyo ${ }^{a}$, Markus Froehlich ${ }^{a}$, Bruce Oniskoj, Kent Matlack ${ }^{a}$, Debendranath Dey ${ }^{a}$, Jaisri R. Lingappa', M. Dharma Prasad ${ }^{a}$, Carsten Korth ${ }^{\mathrm{e}}$, Anatoliy Kitaygorodskyy ${ }^{\mathrm{a}}$, Dennis Solas $^{a}$, Homer Boushey ${ }^{k}$, John Greenland ${ }^{c, k}$, Satish Pillai ${ }^{\mathrm{b}, \mathrm{k}}$, Kumar Paulvannan ${ }^{\mathrm{a}}$, and Vishwanath R. Lingappa ${ }^{\mathrm{a}, \mathrm{k}, \#}$ 


\section{Host-targeted Pan-respiratory Antiviral Therapeutics}

${ }^{\text {a }}$ Prosetta Biosciences, $6705^{\text {th }}$ St., San Francisco, CA 94107

${ }^{b}$ Vitalant Research Institute, 270 Masonic Ave, San Francisco, CA 94118

${ }^{c}$ Veterans Administration Medical Center, 4150 Clement St, San Francisco, CA 94121

d University of Georgia, Animal Health Research Center, 111 Carlton St., Athens, GA 30602

e Institute of Neuropathology, Heinrich Heine University, Düsseldorf, Germany.

${ }^{f}$ Institute of Virology, Medical Faculty, University Hospital Düsseldorf, Heinrich-Heine-

Universität, Düsseldorf, Germany.

${ }^{9}$ Santo Biotech, LLC., 8954 W Fall Creek Dr., Pendleton, IN 46064

${ }^{\mathrm{h}}$ MS Bioworks, Ann Arbor, MI, 48108

'Dept. of Global Health, University of Washington, Seattle, WA 98109

jOnipro LLC., Kensington, CA 94707

${ }^{k}$ University of California, San Francisco, CA 94143

\# To whom correspondence should be addressed 


\section{Host-targeted Pan-respiratory Antiviral Therapeutics}

\section{Abstract}

Antiviral compounds displaying several remarkable features have been identified by a uniquely enabling drug screen and advanced through validation in two animal models, and in human primary bronchial epithelial cells grown to an air-liquid interface (ALI) and infected with SARSCoV-2 (Brazil). Activity is observed in the nanomolar range in mammalian cells in vitro against the six viral families causing most human respiratory viral disease, irrespective of strain, including SARS-CoV-2 delta variant. A substantial barrier to development of viral resistance is demonstrated for influenza (FLUV). The drug target is an allosteric site on a novel host multiprotein complex (MPC) formed transiently, in an energy-dependent fashion, and composed of proteins implicated in viral lifecycles and innate immunity. The composition of this host MPC is modified in viral family-specific ways by FLUV and CoV, and substantially restored to the uninfected state with drug treatment. SQSTM1/p62, a key regulator of the autophagy pathway of innate immunity is i) found in the target MPC from uninfected cells, ii) lost upon infection, and iii) restored by drug treatment of infected cells, as assessed by drug resin affinity chromatography. A small subset of 14-3-3 is identified as the host protein to which the drug is bound. Advanced compounds with good oral bioavailability, half-life, lung exposure, and safety are approaching criteria for a Target Product Profile. We propose these novel drug targets to comprise a previously unappreciated molecular basis for homeostasis that is modified by viruses to facilitate their propagation and is restored by treatment with the therapeutic compounds presented. This discovery has transformative implications for treating respiratory viral-related disease, applicable to everything from COVID-19, seasonal influenza, common 'winter viruses' (respiratory syncytial virus, parainfluenza virus, rhinovirus, etc.), emerging respiratory viruses, and prevention of virus-induced asthma/COPD exacerbations. Treating respiratory viral disease with these host-targeted pan-respiratory viral family active compounds early, upon onset of symptoms of viral upper respiratory infection, irrespective of cause, should protect against progression to lower respiratory tract or systemic infection, the hallmarks of serious illness. 


\section{Host-targeted Pan-respiratory Antiviral Therapeutics}

\section{Introduction}

Viruses are recognized as challenging adversaries for two very different reasons. First, because their reproductive strategy involves reprogramming of host protein machinery in order that it be used to meet their needs rather than those of homeostasis ${ }^{1}$. As a consequence there are only a limited number of virus-specific drug targets, all others having an intrinsic risk of host toxicity. Second, because viral generation time is so much shorter than ours. This allows viruses, particularly RNA viruses, to rapidly evolve mutants that are resistant to virus-targeted therapies, be they vaccines or small molecules ${ }^{2,3}$.

There is, however, a third feature of viruses that is not as obvious as the first two noted above, that provides an overlooked antiviral opportunity. Through natural selection over eons of time, viruses have identified the most valuable of innumerable potential host targets and have refined the best approach to reprogramming those targets to meet their needs. In doing so, they have made discoveries that we have not yet made about human biology and have validated those insights in the practical world of survival of the fittest. If a means could be devised of determining the targets that are most useful to viruses, perhaps that information could be turned to therapeutic advantage against them.

Here we describe results from a highly unconventional host-targeted antiviral screen revealing a new class of such virus-favored host targets. Small molecules with some striking phenotypic features have been identified and advanced. These features include pan-respiratory viral family antiviral activity (with FLUV, SARS-CoV-2, and respiratory syncytial virus [RSV] among the examples, and extending to six viral families demonstrated) and a barrier to resistance development (shown for FLUV). Unexpectedly, some of these host-targeted compounds avoid host toxicity, for reasons that will be described. These findings suggest a 


\section{Host-targeted Pan-respiratory Antiviral Therapeutics}

breakthrough therapeutic strategy for the current COVID-19 pandemic in particular, and respiratory viral diseases in general.

\section{Results}

\section{Probing viral assembly with an orthogonal host-targeted viral protein biogenesis screen}

Cell-free protein synthesis is a biochemical process by which a central event of biology, conversion of the genetic code into the proteins that make life possible, is reduced to reactions occurring in a test tube, during which the nascent proteins of interest can be used to magnify a diversity of otherwise hard-to-detect protein-protein interactions. This has proven a remarkably versatile tool for studying biological mechanisms. For example, it made possible deciphering of the genetic code ${ }^{4}$ and deconvolution of the events in protein targeting ${ }^{5}$, two centerpiece achievements of modern molecular and cell biology. This tool has since been adapted to the study of viruses: cell-free protein synthesis and assembly (CFPSA) systems enabled insights into the mechanism of viral assembly $y^{6,7,8}$ that were corroborated in cells by other methods with painstaking effort ${ }^{9}$. Applied to drug discovery, this approach has identified small molecules termed assembly modulators, which have novel, host-targeted mechanisms of antiviral action. The host MPCs on which these compounds are active have been termed assembly machines by virtue of their ability to catalyze viral capsid assembly ${ }^{10,8,11}$.

Here we have utilized the same approach to study the biogenesis of viruses implicated in severe respiratory disease and discovered compounds active at blocking their assembly. As a starting point, we began with FLUV, a member of the family Orthomyxoviridae. By analogy to previous studies on human immunodeficiency virus (HIV) $)^{10,11}$ and rabies virus ${ }^{8}$, FLUV nucleoprotein (NP), the major capsid protein, was expressed together with other FLUV gene products including the matrix protein (M), in the CFPSA system. We observed a putative capsid assembly pathway (Figure $1 \mathrm{~A})$, roughly analogous to the pathways observed previously for 


\section{Host-targeted Pan-respiratory Antiviral Therapeutics}

other viral families, progression of whose assembly intermediates to the final structure is energy-dependent ${ }^{8,9,12,12-15}$. Assembly was assessed by co-migration of multiple newly synthesized FLUV gene products in the final sucrose step gradient (ssg) peak. The timedependent high molecular weight peak in fraction 10/11 was subsequently analyzed by iodixanol buoyant density gradients (idxg), and showed multiple viral gene products comigrating in the expected buoyant density range of authentic FLUV particles ${ }^{16}$. Expression of the capsid proteins of other respiratory viral families, including SARS-CoV-2, a member of the family Coronaviridae (Figure 1B), and RSV of the family Paramyxoviridae (data not shown), also displayed similar assembly pathways, albeit with features distinctive to each viral family. In summary, CFPSA assembly studies suggested that the same approach that has been used successfully to generate unconventional host-targeted antiviral small molecules for $\mathrm{HIV}^{17}$ and rabies $^{8}$ could be applied to diverse respiratory viruses.

Antibodies recognizing the FLUV NP were used to establish an ELISA-style plate assay for FLUV capsid assembly (Figure $2 \mathrm{~A})^{16}$ as previously achieved for rabies virus, rift valley fever virus (RVFV) and $\mathrm{HIV}^{8,17,18}$. A portion of a 150,000 drug-like small molecule library was screened and a number of hits identified from completely different chemical classes (Tanimoto similarity coefficient $<40 \%$ ), three of which were advanced by medicinal chemistry analog synthesis (Figure 2B). Activity in the CFPSA screen correlates with activity against infectious virus in cell culture (Figure 2C), demonstrating the fidelity of the CFPSA screen.

\section{Medicinal chemistry advancement of a FLUV assembly modulator}

One of these FLUV-active chemotypes was taken as the lead starting point for advancement (Table 1). The parent compound structure was noted to have a 1,3 benzodioxan core. Due to the limited commercial availability of building blocks with a 1,3-benzodioxan core, a pyrazole carboxamide library of analogs containing a simple alkoxy phenyl ring was synthesized 


\section{Host-targeted Pan-respiratory Antiviral Therapeutics}

and screened for efficacy against FLUV in cell culture (Table 1). Initial screening resulted in the identification of a non 1,3-benzodioxan core-containing compound with antiviral activity in the micromolar range, PAV-773. The weaker activity of PAV-1866 shows the importance of an unsubstituted secondary amide.

Considering the metabolic susceptibility of the tert-butyl group ${ }^{19}$ and to improve pharmacokinetic (PK) properties, various C-3 substituted pyrazole carboxamides were prepared and tested (Table 1 compounds PAV-854, PAV-530, and PAV-835). Based on the activity and other properties of PAV-835, a pyrazole carboxylic acid with a C-3 cyclopropyl group was the choice of acid for subsequent pyrazole carboxamide analogs. To study the impact of the pyrazole regioisomer (3-cyclopropyl-1-methyl-pyrazole-5-carboxylic acid vs 5-cyclopropyl-1methyl-pyrazole-3-carboxylic acid), the regioisomer of PAV-835 was prepared using 5cyclopropyl-1-methyl-pyrazole-3-carboxylic acid and tested, found inactive, and not further pursued in our antiviral program.

In view of the substantial activity observed, we proceeded with rodent PK and toxicology studies (Supplementary Tables 1 and 2). Acute repeat dose toxicity was evaluated in BALB/c mice with $2 \mathrm{mg} / \mathrm{kg}$ daily doses for 10 days through intraperitoneal injections. No significant differences were observed between the control and study group with respect to hematology, differential leucocyte count and clinical chemistry. Also, there was no significant variation in the weight between control and study group animals. No abnormalities were observed in histopathological investigations (Supplementary Table 2).

Following these successes, further improvement of the lead series was attempted. Keeping the cyclopropyl as the preferred C-3 substituent, analogs were made to optimize druglike properties. Selected results are shown in Table 2. Based on the overall data PAV-431 was 


\section{Host-targeted Pan-respiratory Antiviral Therapeutics}

taken as an advanced analog superior to the earlier compounds assessed. The synthetic scheme for PAV-431 is shown in Supplementary Figure 1.

\section{Pan-respiratory viral family antiviral activity}

The early FLUV compounds were counter-screened against other viral families by assessing viral titer in cell culture by $\mathrm{TCID}_{50}$ determination. These studies revealed strong efficacy against the Coronaviridae. Therefore we proceeded with an animal efficacy trial (Figure 3). The testing model involved randomizing newborn piglets from separate litters into control and treatment groups, then infecting all with porcine epidemic diarrhea virus (PEDV), a member of family Coronaviridae, and assessing efficacy of just two intramuscular doses of early lead series compounds (PAV-773 and PAV-835) versus vehicle on survival, which was found to be significant (Figure 3). Recognizing that, as with COVID-19, there is no way to predict those at risk of severe disease, each litter of newborn piglets was separately randomized to control and treatment groups allowing retrospective analysis of the treatment groups of those litters whose control groups demonstrated mild vs severe disease. As anticipated, a subset of litters manifested severe disease in the form of $100 \%$ death of the control group; efficacy observed in that subset of the treatment group was no different from that observed for all drug-treated animals, indicating equal efficacy against mild and severe disease (Figure 3B).

In view of the COVID-19 pandemic, activity of PAV-431 against SARS-CoV-2 (Washington) was assessed and found efficacious by plaque assay, the gold standard for cell culture infectivity determination (Figure $4 \mathrm{~A}$ ), with $\mathrm{EC}_{50}$ of $100 \mathrm{nM}$. Assessment of PAV-431 against SARS-CoV-2 (delta) confirmed that activity was not SARS-CoV-2 strain-specific (Figure 4B). A second, structurally distant (Tanimoto coefficient $<30 \%$ ) backup assembly modulator chemotype represented by PAV-617 also demonstrated $100 \mathrm{nM} \mathrm{EC}_{50}$, indicating that the SARSCoV-2 antiviral activity observed is not limited to the lead chemotype. The initial screening of 


\section{Host-targeted Pan-respiratory Antiviral Therapeutics}

compounds had been performed on FLUV A strain WSN/33 using a TCID 50 assay. Efficacy of the lead and backup chemotypes were confirmed on swine FLUV (SIV), and, in order to allow BSL-2 target identification studies on bovine coronavirus (BoCoV, Figure 4C). Additionally, PAV-431 was assessed against RSV strain A-2, adenovirus serotype 5 strain adenoid 65, human cytomegalovirus strain $A D-69$, and human rhinovirus 16 , together representing all six major respiratory viral families infecting humans (Orthomyxoviridae, Coronaviridae, Paramyxoviridae, Adenoviridae, Herpesviridae, Picornaviridae respectively). All were found to be highly sensitive to this compound $\left(\mathrm{EC}_{50} \leq 100 \mathrm{nM}\right.$ by $\left.\mathrm{TCID}_{50}\right)$, while a member of a nonrespiratory viral family, rabies virus (family Rhabdoviridae) was much less so (Figure 4C). Remdesivir, a compound FDA-approved for SARS-CoV-2 infection was assessed similarly and revealed an $\mathrm{EC}_{50}$ approximately 16 fold weaker than that of PAV-431 (data not shown).

A second animal trial was carried out, in this case with the more advanced compound PAV-431, in the cotton rat infected with RSV, a model that allows accurate determination of viral titer $^{20}$. This study observed a significant drop in viral titer upon drug treatment (Supplementary Figure 2), providing a quantitative assessment to complement efficacy assessed by survival as observed in the earlier pig trial (Figure 3). As the effect on viral titer was modest compared to that of the far weaker earlier compounds on survival in the pig trial, we suspected that a substantial portion of the efficacy of these compounds came from other actions, e.g. on innate immunity, as will be discussed below.

Several additional studies, including hERG channel inhibition and Ames test assessment, were performed on compound PAV-431, revealing no significant liabilities, and putting the lead series close to achievement of a target product profile indicating suitability for advancement to investigational new drug (IND)-enabling studies (Supplementary Figure 3). Additional analogs varying substituents on the R4-R8 positions of the phenyl ring were 


\section{Host-targeted Pan-respiratory Antiviral Therapeutics}

synthesized and tested, resulting in the identification of molecules with substantially improved PK properties (for example > 10x improved exposure, Supplementary Table 1).

\section{Evidence for a barrier to resistance development}

In principle, a host target should provide a greater barrier to resistance since the virus is not the immediate drug target. Thus, the rapid mutation capacity of the virus is tangential and while development of resistance may not be impossible, its progression would be expected to be difficult and therefore slow. Accordingly, assembly modulators active against HIV and other retroviruses have shown an impressive barrier to resistance development ${ }^{17}$. We assessed the capacity of FLUV to develop resistance to the present lead chemotype (represented by PAV835) and one of the backup chemotypes (represented by PAV-333). We found no resistance development to either chemotype, in parallel with substantial development of resistance to oseltamivir, a small molecule targeting a virally encoded enzyme (Table 3). The assembly modulator active against multiple Retroviridae and shown to have a barrier to resistance development for $\mathrm{HIV}^{21}$, is not active on FLUV $\left(\mathrm{EC}_{50}>800 \mathrm{nM}\right)$. Thus, the barrier to resistance development is likely to be a general property of assembly modulators.

\section{Evidence for an unconventional host target}

As the initial screen was a phenotypic screen for capsid assembly, albeit carried out in a cell-free system rather than in a living cell, we did not initially know the molecular target(s) on which the compounds act. In order to glean insight into the target, drug resin affinity chromatography (DRAC) was utilized. Drug-resin conjugates of compound PAV-431 were constructed by attachment to the pyrazole nitrogen (Supplementary methods; Supplementary Figure 1B). The "surrogate ligand" (drug with an added linker but not attached to the resin) displayed antiviral activity against FLUV comparable in magnitude to PAV-431 itself. Thus, the chosen resin attachment point was not essential for antiviral activity and made possible the 


\section{Host-targeted Pan-respiratory Antiviral Therapeutics}

construction of drug resins for use as affinity ligands for target identification. Cellular extracts were applied to the drug resin, washed extensively, bound proteins eluted with free drug to reveal specific binding of a set of host proteins, as will be described below. Similar protein profiles were observed upon elution with the surrogate ligand rather than free drug.

Early in the course of these studies two profound observations were made with regards to the drug target and the use of DRAC for its identification. First, that the inclusion of nucleotide triphosphates and an energy regenerating system (creatine phosphate and creatine kinase) and carrying out both binding and elution from the drug resin at room temperature $\left(22^{\circ} \mathrm{C}\right)$ rather than $4^{\circ} \mathrm{C}$, resulted in a substantial increase in the specific proteins bound and eluted with free drug, compared to identical conditions in the absence of metabolic energy or at $4^{\circ} \mathrm{C}$ (Supplementary Figure 4A). Both the binding step and the free drug elution step were found to be independently nucleotide triphosphate dependent. This suggested that the drug target was a dynamic MPC whose component proteins joined together as a multimer only transiently requiring consumption of metabolic energy and whose subsequent release from the drug ligand also required metabolic energy. All subsequent DRAC studies were performed under these conditions, a protocol distinguished by the acronym eDRAC, which greatly enhanced target detection.

The second observation was that the fraction of any given protein found in eDRAC free drug eluates was small compared to the total amount of that protein present in the initial starting extract applied to the drug resin(<5\%). Rerun of the target-depleted flow-through on a fresh eDRAC column showed little additional binding, implying that the small fraction initially bound was all that was available for binding. The identical extract applied to a control resin (lacking the drug affinity ligand) showed no specific binding. When the flow-through from the control resin was subsequently applied to the PAV-431 drug resin, it showed most of the expected binding to the drug resin (Supplementary Figure 4B). Thus, the lack of binding of the drug resin flow 


\section{Host-targeted Pan-respiratory Antiviral Therapeutics}

through to a second drug resin column cannot be fully explained by degradation or other changes to the target MPC. Rather it argues that the target had been largely depleted by passage over the first drug resin. This in turn, implies that the target of the assembly modulator drug represents an exceedingly small fraction of the total of each of its component proteins in the cell. VCP/p97, also known as transitional endoplasmic reticulum ATPase, is a key protein for which this is true (Supplementary Figure 4).

These two observations have been demonstrated for extracts prepared from various cell lines competent for infection with both FLUV and BoCoV, including MDCK cells (Supplementary Figure 4A), HRT-18G cells (Figure 6A), and MRC-5 cells (Figure 5). Likewise, extracts were prepared from uninfected pig lungs to compare a heterogeneous but physiologically more faithful tissue to the homogeneous cell lines and gave similar results (Supplementary Figure 4B). The implications of these two observations are profound in different ways, and together may explain why the present findings have not been discovered previously, as will be discussed.

For detailed characterization of the target we used extracts of human MRC- 5 cells, either uninfected or infected with either BoCoV or FLUV, applied to the drug resin, extensively washed, and the bound target eluted with free drug, all done with an energy-regenerating system in view of the above observations. The eluates were initially analyzed by silver stain (Figure 5A) and tandem mass spectrometry (MS-MS, Figure 5B-E). To demonstrate the specificity of the approach we compared the free drug eluate from uninfected cell extract applied to the drug resin to the free drug eluate from a control resin (lacking the drug as ligand, and therefore to which there should be no specific binding/free drug elution). We observed a set of proteins statistically significantly unique to the drug resin eluate. This provided a baseline from which to assess i) the effect of infection with CoV or FLUV, and ii) the corresponding effect of 
Host-targeted Pan-respiratory Antiviral Therapeutics

treatment of infected cells with PAV-431 for $24 \mathrm{hrs}$ prior to preparing the extracts to be applied to the drug resin (see Supplementary Figure 5).

\section{Mass spectrometry of drug resin eluates from uninfected, infected and treated cells}

In the BoCoV-infected/DMSO-treated vs. Uninfected/DMSO-treated eDRAC eluates, we identified 86 significant proteins. Based on the calculated log2 fold change of LFQ-intensities and p-values, 56 of those proteins were enriched (log2 fold change $>1$ ) in BoCoV-infected DMSO-treated eDRAC eluates, 23 were unchanged $(-1<\log 2$ fold change $<1)$, and 7 were decreased (log2 fold change<-1) compared to uninfected/DMSO-treated eDRAC eluates (Figure $5 B$, left). Upon treatment with PAV-431, the protein content of the eDRAC eluate changed: 5 proteins were enriched compared to uninfected/DMSO-treated eluates, 79 were equal to uninfected/DMSO-treated eluates, and 2 were decreased compared to uninfected/DMSOtreated eluates (Figure 5B, right).

In the FLUV-infected/DMSO-treated vs. Uninfected/DMSO-treated eDRAC eluates, we identified 95 significant proteins. The 86 proteins from the BoCoV-infected eluates and the 95 proteins from the FLUV-infected eluates had 72 proteins in common. Based on the calculated log2 fold change of LFQ-intensities and p-values, 64 of the 95 proteins in the FLUV-infected eDRAC eluate were enriched in FLUV-infected/DMSO-treated eDRAC eluates, 18 were unchanged, and 13 were decreased compared to uninfected/DMSO-treated eDRAC eluates (Figure 5C, left). Upon treatment with PAV-431, the protein content of the eDRAC eluate changed: 23 proteins were enriched, 72 were unchanged, and 0 were decreased compared to uninfected/DMSO-treated eluates (Figure 5C, left).

The 86 proteins from the BoCoV-infected eluates were searched for in publications on the host proteins involved in the coronavirus virus-host interactome. 16 host proteins from the 


\section{Host-targeted Pan-respiratory Antiviral Therapeutics}

eluates were found to be involved in the coronavirus lifecycle ${ }^{22,23}$. These 86 proteins were also searched in the Reactome database for enriched pathways. 22 proteins in the BoCoV-infected eluates were identified as part of the innate immune system interactome. The 95 proteins from the FLUV-infected eluates were searched in the literature and the VirusMentha database. 59 proteins from the eluates were found to be part of the FLUV lifecycle ${ }^{24,25}$. These 95 proteins were also searched in the Reactome database for enriched pathways. 28 proteins in the FLUVinfected eluates including 21 shared between the two viral families, were identified as part of the innate immune system.

Shown for each virus are the three lists of proteins found significant by LC/MS-MS for each of the two viruses studied (Figure 5D, E). The lists of proteins are ordered from top to bottom in terms of their known involvement in innate immune functions, and then those known to be involved in the lifecycles of each viral family (CoV and FLUV). Upon PAV-431 drug treatment a striking degree of restoration to the uninfected state was achieved, for both host proteins involved in the lifecycle of each virus, and in innate immune functions, especially for BoCoV but also to a significant extent for FLUV.

Analysis of the data by spectral count rather than LFQ intensity is provided in Supplementary Tables 4 and 5 .

Several of the proteins found in both uninfected and infected cell lysates were notable. For example, VCP/p97, is a multi-functional host protein ${ }^{26}$ implicated in the lifecycles of both FLUV $^{22,24}$ and BoCoV 22,27 . VCP/p97 is present in the eDRAC eluates from uninfected cells, strikingly enriched in the eDRAC eluates from both FLUV and BoCoV infected cells, and restored close to normal levels in the eDRAC eluates upon drug treatment of BoCoV-infected samples. However, it remains elevated in the eDRAC eluates from drug-treated FLUV-infected 


\section{Host-targeted Pan-respiratory Antiviral Therapeutics}

samples (Figure 5E). These data are consistent with the hypothesis that a host assembly machine containing VCP/p97, seen as its normal composition in uninfected cells, is altered during infection to form an aberrant assembly machine that contains additional VCP/p97, in order to meet the needs of the virus rather than the host. Assembly modulator drug-treatment substantially restores normal assembly machine composition, including for VCP/p97, at least in the case of BoCoV-infected cells.

In addition to proteins identified by MS-MS, western blotting (WB) was performed to confirm key MS-MS findings and to detect proteins that might have been missed in the MS-MS analysis. In light of the unexpected observation of energy-dependence of target detection, and that the eDRAC free drug eluates represent a single digit percentage subfraction of the total cellular abundance of each of the identified proteins, we were alert to the possibility that important proteins present in the eDRAC eluates might be missed by a single method of detection, such as MS-MS.

One protein in particular, missing by MS-MS analysis but readily detected by WB, was Sequestosome 1 (SQSTM1/p62), a key regulator of the autophagy pathway, a crucial limb of innate immunity ${ }^{28-30}$. Monospecific commercial antibodies showed the clear presence of an SQSTM1/p62 band at the correct size in the uninfected eDRAC eluate cells (Figure 6A). This band was substantially diminished in the eDRAC eluate from either FLUV or BoCoV infection. Moreover, treatment of infected cells with either of two structurally distinct assembly modulator compounds, PAV-431 and advanced analog PAV-818 of the backup chemotype compound PAV-617 studied in Figure 4A, significantly restored SQSTM1/p62 to the eDRAC eluates. SQSTM1/p62 interacts directly with vimentin and HSP5a (an HSP70 family member) by interactome analysis ${ }^{31}$ both of which are enriched in the eDRAC eluates upon infection and depleted upon drug treatment (Figure 6B). While additional studies are needed to fully 


\section{Host-targeted Pan-respiratory Antiviral Therapeutics}

understand these observations, they are consistent with our working hypothesis on viral manipulation of innate immunity, and will be discussed below.

In view of the insights provided by eDRAC, we adapted the same position on PAV-431 that had been used for eDRAC, for photocrosslinking. Instead of attachment to resin, the same side group was modified by addition of a diazirine and biotin moiety. The synthetic scheme by which the crosslinker analog was synthesized is described in methods. eDRAC was carried out as previously described, but the photo-crosslinker was used in place of free drug to elute from the resin. The resulting eluate was exposed to UV light at $355 \mathrm{~nm}$ as described, in the presence or absence of free drug, and the crosslinked adducts assessed by SDS-PAGE and WB probed with streptavidin-alkaline phosphate (Figure 6C). The nearest neighbor protein to the crosslinker-modified drug should be the one that is most diminished by the presence of free drug, while those less so may represent non-specific crosslink products. One band, at approximately $28 \mathrm{kDa}$ is strikingly diminished by the presence of free drug, suggesting it as the direct drug-binding protein. Streptavidin Sepharose precipitation under native vs denatured conditions followed by WB was used to distinguish proteins that are a part of the larger MPC target vs the protein to which the drug was directly bound and covalently crosslinked (Figure 6D). The eDRAC crosslinker eluate after exposure to UV light was divided into two aliquots, one of which was denatured by addition of SDS to $1 \%$ in the presence of $1 \mathrm{mM}$ dithiothreitol as a reducing agent, heated to $100 \circ \mathrm{C} / 3$ minutes, cooled and diluted with $20 \mathrm{x}$ volume of $1 \%$ Triton-X100-containing buffer (to take up all free SDS into non-denaturing Triton-X-100 micelles), while the other aliquot was comparably diluted but maintained native. Streptavidin Sepharose beads were added to both aliquots and after incubation with mixing and washing, the biotinylated proteins bound by the streptavidin Sepharose beads were analyzed by SDS-PAGE and WB for various proteins present in the starting eDRAC eluate. In the denatured sample, the proteins comprising the target MPC are no longer together, so only the direct drug-binding protein will be 


\section{Host-targeted Pan-respiratory Antiviral Therapeutics}

precipitated by the streptavidin Sepharose beads (because it is covalently attached to the biotin moiety). In the native sample, the proteins comprising the target MPC are still together, so all can be detected, e.g. by WB of the washed streptavidin Sepharose precipitate. As can be seen, VCP/pp97, p62/SQSTM1, and CAPN2 are identified by WB of streptavidin precipitates under native but not denatured conditions, indicating that they are present in the MPC drug target, but are not direct drug-binding proteins since they are lost upon denaturation. However WB for 143-3 identified it as present under both native and denatured streptavidin precipitation conditions (Figure 6D), confirming the expectation from Figure $6 \mathrm{C}$ that a $28 \mathrm{kDa}$ protein is the direct drugbinding candidate.

\section{Advanced compounds approaching clinical candidate nomination}

Further structure-activity relationship optimization allowed us to identify analogs by eDRAC that were far more potent than PAV-431 both in transformed cell culture models and in primary human bronchial epithelial cells cultured to an air-liquid interface ${ }^{32}$ (Figure 7). Analogs PAV-471 and PAV-104 were particularly interesting because while they are both $>10 x$ more potent than PAV-431, PAV-471 is substantially more toxic (maximum tolerated dose in mice of 2mg/kg IP compared to $10 \mathrm{mg} / \mathrm{kg}$ for PAV-431), while PAV-104 maximum tolerated dose was $>20 \mathrm{mg} / \mathrm{kg}$ IP (Figure 8A). Indeed PAV-104 has pharmacokinetic properties consistent with those desired for a clinical candidate, displaying good oral bioavailability (32\%), half-life (9hrs), and lung exposure (2.3x plasma level at $24 \mathrm{hrs}$ ) as summarized in Figure 8A. Moreover oral dosing of rats with $50 \mathrm{mg} / \mathrm{kg}$ daily for 7 days showed no toxic signs of any sort. Trough blood levels on the $7^{\text {th }}$ day were $\sim 200 x \mathrm{EC}_{50}$ with no evidence of toxicity (Figure $8 \mathrm{~B}$ ). These features lead to a prediction regarding the specificity of PAV-471 vs PAV-104, as described below. 


\section{Host-targeted Pan-respiratory Antiviral Therapeutics}

\section{Testing predictions of the working hypothesis}

We have previously interpreted work on rabies virus ${ }^{8}$ and $\mathrm{HIV}^{17}$ to suggest that a normal transient and dynamic host MPC assembly machine involved in host homeostasis is modified by viral infection to form an aberrant assembly machine to facilitate viral propagation (Figure 9A). We further hypothesized that assembly modulator drug-treatment modifies the aberrant assembly machine in a manner that triggers restoration of homeostasis. Restoration could be either a simple return to normal assembly machine composition or proceed by a more complex and indirect route. For example this might involve directing the aberrant assembly machine to the autophagic pathway, with a homeostatic feedback loop resulting in restoration of the normal assembly machine by re-synthesis (Figure 9B). In any event, these hypotheses make a series of predictions that are testable.

A first prediction is that if the eluate comprises a discrete MPC rather than numerous individual proteins binding specifically or non-specifically to the drug resin, that should be demonstrable by photo-crosslinking with a drug analog where a photoactivatable diazirine group and a biotin moiety are attached at the same position used to make the resin conjugate (see Supplemental methods). This was confirmed in Figure 6D with the detection of a subfraction of the protein 14-3-3 as the protein to which the drug was crosslinked by exposure to UV light and precipitated under both native and denaturing conditions.

A second prediction connects the observed antiviral activity of assembly modulator compounds and the method used to find them in the first place. We interpret the data presented to show that assembly modulators have their antiviral activity by virtue of targeting an allosteric site controlling host assembly machine composition, and that the consequences of this action are deleterious to the virus. If this is the case, then treatment with those compounds should either grossly disrupt the pathway by which the viral capsid is formed, or through more subtle 


\section{Host-targeted Pan-respiratory Antiviral Therapeutics}

effects result in formation of a capsid whose structure is somehow aberrant (thereby rendering the viral particle non-infectious). Moreover one (or both) of these alternatives should be demonstrable by CFPSA. The former possibility is confirmed for SARS-CoV-2 capsids by demonstrating that PAV-431 treatment during synthesis in the CFPSA system disrupts assembly of NP with M in ssg analysis (Figure 10A). The latter possibility is observed for FLUV capsids synthesized in the presence of PAV-471. While they do not show disruption of NP and M co-migration on ssg, when the putative completed capsid fraction is further analyzed for buoyant density by idxg compared to DMSO-treated control, aberrant capsid formation is observed in a drug dose-dependent fashion (Figure 10B). Thus, the two different respiratory viral families so studied, while both susceptible to the same host-targeted drugs (Figure 4 and 7), display different drug-induced assembly-defective phenotypes by CFPSA. Presumably this reflects different evolutionary choices made by each of the two viral families in their struggle with the host. Future studies using these methods and others should allow a better understanding of the molecular basis for these differences.

A third prediction is based on the expectation that a compound selective for the virusinduced aberrant assembly machine should be non-toxic to the host while retaining potency against the virus, as has been demonstrated for PAV-104 in Figure 8B and Figure 7, respectively. In contrast, the comparably potent but not aberrant assembly machine-selective PAV-471 is, as expected, far more toxic to the host than is PAV-104. Likewise, the weaker PAV431 has substantial host toxicity despite its lower anti-viral activity because it too is not aberrant assembly machine-selective. Our explanation for the divergence of toxicity and efficacy in the case of PAV-104 is that structure-activity relationship optimization had advanced the lead series to aberrant assembly machine selectivity. If so, a straightforward prediction is that a protein present in both normal and aberrant assembly machines should be preferentially eluted from PAV-431 drug resin by an aberrant assembly-selective drug such as PAV-104, only from 


\section{Host-targeted Pan-respiratory Antiviral Therapeutics}

infected cell extracts but not from uninfected extracts. In contrast, PAV-471 is not aberrant assembly machine selective and so would be expected to elute comparable amounts of shared target proteins from both uninfected and infected cells (Figure 11A). This is confirmed in Figure 11B where uninfected vs rhinovirus-infected A549 cell extracts are applied to the PAV-431 drug resin. As monitored by both the direct drug-binding protein 14-3-3 and the non-nearest neighbor member of the host MPC target, VCP/p97, PAV-104 elutes substantially more of the MPC target from infected cells compared to uninfected cells, as predicted, and measured by those two signature proteins (Figure 11B). Remarkably, as noted previously and confirmed again here, the target of both potent compounds is a small subfraction of the total cellular balance sheet of the two assembly machine component proteins studied (VCPp97 and 14-3-3), comprising < 5\% of the total of each protein in the cell extract (see y axis of Figure 11).

\section{Discussion}

\section{An orthogonal approach to drug discovery}

Drug discovery using CFPSA systems as described here has made possible the detection and interrogation of a novel class of transient and energy-dependent host MPC targets, which we term assembly machines. That in turn enabled the identification of compounds that appear to modulate this newly described host machinery in ways that display potent antiviral activity. The drugs themselves were then used as energy-dependent affinity ligands to identify aberrant assembly machines resulting from viral infection, and to drive the structure-activity relationship to aberrant assembly machine selectivity. The culmination of this effort are compounds potent against respiratory viruses without apparent toxicity to the host. A number of features of this approach are notable.

Let us consider the drug screen used. Most phenotypic screens involve whole cell assays $^{33}$. Such screens, while often successful, face significant liabilities. The presence of 


\section{Host-targeted Pan-respiratory Antiviral Therapeutics}

confounding events in the complex milieu of a living cell can mask detection of a potentially interesting target. Moreover, in phenotypic screens the target is unknown at the time of hit generation and often even through lead optimization. Cellular physiological, feedback effects are typically complex and multi-faceted ${ }^{34,35,36,37,38,39,40,41,42,43}$. This in turn creates a signal-tonoise problem with regards to parsing of several potential contributing targets to a particular phenotypic effect. Even when multiple contributors are identified, deciding which is the one to pursue for therapeutics can be problematic.

By contrast, the CFPSA-based phenotypic screening approach taken here focuses attention on those events occurring early in protein biogenesis (during and immediately after protein synthesis) and recreates them in slow motion. This results in an improved signal-tonoise ratio by excluding much of the rest of the lifecycles of most proteins, of both viruses and cells, from experimental interrogation. Moreover, compounds too toxic to assess in intact cells may be screened by CFPSA, with the toxic features removed later. A growing literature supports the notion that protein assembly is co-translational ${ }^{44-46}$; thus it should not be surprising that CFPSA reveals aspects of the viral lifecycle not discernable by other experimental approaches, and enables the discovery of drug targets that had not been previously detected. This is precisely how cell-free protein synthesis facilitated dissection of the pathways of protein targeting ${ }^{5}$.

The compounds initially identified by CFPSA typically recognize both the host's normal assembly machine and the aberrant assembly machine optimized for the needs of the virus. That method, while effective at detecting targets that other screening methods could not, may be insufficient to achieve the further goal of driving the structure-activity relationship to high potency with low host toxicity necessary to convert the hit compound into a drug. However, with eDRAC-based structure-activity relationship optimization, it is possible to identify analogs that 


\section{Host-targeted Pan-respiratory Antiviral Therapeutics}

are both potent against the virus and, by virtue of their aberrant assembly machine selectivity, non-toxic to the host. Thus, while each of these new biochemical tools, CFPSA and eDRAC are powerful in their own right, only together could they have driven the structure-activity relationship to potency against the virus with non-toxicity to the host, as demonstrated here for PAV-104.

\section{A novel class of drug targets}

We interpret the data presented to suggest a class of highly heterogeneous and dynamic host MPCs, termed assembly machines, perform a range of assembly-relevant tasks to maintain homeostasis. The properties demonstrated here for assembly machines, in particular their transience and energy-dependence for both formation/binding and elution/action, may explain why they have been largely overlooked for anti-viral drug discovery to date. Viruses have, over deep evolutionary time, become adept at co-opting host machinery to their needs ${ }^{1}$, including and perhaps especially, assembly machines. The needs of the virus include both capsid formation and misdirection of innate immunity, which might otherwise be summoned to impede viral propagation. The virus has found an allosteric site of a subset of the protein 14-3-3 that appears to achieve both goals. CFPSA and eDRAC as presented here, have allowed to us advance to one small molecule, PAV-104, that seems to checkmate the virus on both counts by modulation of that allosteric site. Exactly how this occurs remains to be further studied. Two remarkable features revealed by the MS-MS data in Figure 5 are worth noting, however. First that a single allosteric site drug target is utilized by the diversity of viruses that cause human respiratory disease. Perhaps that should not be surprising since trophism for the lung is a shared phenotype of those viral families despite the differences in their size, structure, receptors used, and life cycles. Moreover, the direct drug-binding protein identified, 14-3-3, has been implicated in the pathophysiology of many different respiratory viral families ${ }^{47,48,49,50}$. 


\section{Host-targeted Pan-respiratory Antiviral Therapeutics}

A second observation from the MS-MS data in Figure 5 is that treatment with one drug substantially restores to normal the diverse aberrant assembly machines created by infection with different viral families. At present one is left to ascribe this unexpected feature to aspects of MPC allostery that remain to be better understood ${ }^{51}$. What is worth noting is that further work with the tools presented here should make possible better answers to this and other questions.

\section{Implications of energy dependence and protein heterogeneity}

If as our data suggests, independent energy-dependent steps are involved in the formation/binding of an MPC to an affinity ligand (in this case the drug), and for release from the affinity ligand, then the discovery of this new class of targets may have impact far beyond the therapeutics of respiratory viruses described here. Energy-dependent MPC target formation may have similarly eluded detection by conventional proteomics in other therapeutic areas.

With regards to protein heterogeneity, if only five percent or less of a given protein represents the subset found in an MPC target of interest (as demonstrated here for both VCP/p97 and 14-3-3), then efforts focusing on that gene product by methods that don't allow subset discrimination may fail to detect the relevance of that subset for the target of interest. It should be noted that a burgeoning literature on the multifunctionality of proteins ${ }^{1,52}$, including in viral infection ${ }^{1,53}$, suggests that the widespread conventional use of recombinant proteins in classical "pull down" assays and yeast 2-hybrid screens may miss an important degree of nuance in protein-protein interactions that are captured by the methods used here. Indeed, some evidence suggests that the $>95 \%$ of any given protein that is not in the MPC assembly machine drug target is itself highly heterogeneous ${ }^{8,54}$. However that possibility has not been further studied here. Regardless, the degree of heterogeneity described here, e.g. for VCP/p97 or 14-3-3, implies that modern genetic methods including both siRNA knockdown and CRISPR, while extraordinarily powerful, may be instruments too blunt for an understanding of gene 


\section{Host-targeted Pan-respiratory Antiviral Therapeutics}

expression as it applies to this dimension of disease therapeutics. Put another way, the information content of the genome is much greater than that revealed by the sequence of nucleotides that codes for the sequence of amino acids within a protein. Additional layers of information are manifest through covalent post-translational modifications ${ }^{55}$, alternate pathways of folding ${ }^{56,57}$ and MPC heterogeneity ${ }^{58}$ none of which can be interrogated by the above conventional methods.

\section{Implications of allosteric modulation of assembly machine composition and action}

Another observation is that the drug binding protein within the assembly machine, 14-3-

3 , is a known allosteric modulator of protein kinases, implicated in particular in viral manipulation of signaling pathways ${ }^{59}$, including by SARS-CoV-2 ${ }^{50}$, albeit involving an allostery more complex than classical descriptions ${ }^{51}$. Several indirect lines of evidence suggest this, including the energy-dependence of drug binding and elution and the change in protein composition of the eDRAC eluted MPC observed with infection different for each of the two viral families studied (FLUV and CoV). Presumably the protein composition of this MPC is altered upon infection as a consequence of virus-induced signaling pathway manipulation, perhaps through metabolite binding-induced conformational change at the same or another allosteric site. The striking return to the eDRAC composition of the uninfected state upon treatment, seen in BoCoV infection (Figure 5D), is consistent with the hypothesized drug-induced normalization of assembly machine composition through allosteric modulation (Figure 9).

Formation of aberrant FLUV capsids in the presence of drug (Figure 10) may explain the maintenance of robust antiviral efficacy against both FLUV and CoV, despite incomplete normalization of eDRAC eluate upon treatment for FLUV compared to CoV (Figure 5). However there are other possibilities to be explored. In vivo, autophagy or other pathways triggered by allosteric feedback loops likely allow completion of assembly machine normalization in the face 


\section{Host-targeted Pan-respiratory Antiviral Therapeutics}

of the immediate stalemate between the drug-treated host and the virus. Alternatively, assembly machine normalization may simply take longer than the $24 \mathrm{hr}$ post-drug treatment time point studied here. In these regards, the rapid restoration of SQSTM1/p62, a known regulator of autophagy, to the target MPC after $24 \mathrm{hrs}$ of drug treatment may be significant. These changes likely reflect evolutionarily-selected signaling pathway modulation that allows the virus to redirect critical machinery away from homeostatic balance and towards the needs of the virus. We propose those viral efforts can be blocked, reversed, or redirected by assembly modulator small molecules, perhaps acting in an antagonistic fashion at the same allosteric sites at which viral manipulation was an agonist of aberrant assembly machine formation.

A practical application of our findings is that select assembly modulator compounds appear to be therapeutic for multiple families of viruses causing respiratory disease. Yet this antiviral effect is selective, since the compounds appear substantially less active on rabies virus, a non-respiratory viral family tested (Figure $4 C$ ). Activity across diverse respiratory viral families suggests that, despite their differences in structure and lifecycles, these viral families have at least one host drug-binding site in common. Whether 14-3-3 is the only protein composing the drug-binding site remains to be determined. As work in the assembly modulation paradigm is at an early stage, many other variations on this theme still remain possible, or may be true in specific cases. We cannot rule out for example that only a subset of the proteins found are part of the particular transient MPC assembly machine responsible for the antiviral effects, and that some of the proteins identified by MS-MS are in other MPCs that share the same drug-binding site that made isolation by virtue of the affinity ligand possible. This may account for the ability of the drug to both interfere with virus assembly and restore p62 to the eDRAC eluate, which may be separate, albeit interconnected, actions. Likewise, the very concept of a single drug binding site may have to be revised for these novel allosteric site targets whose engagement changes the composition of a MPC target rather than simply blocking it. Perhaps a better 


\section{Host-targeted Pan-respiratory Antiviral Therapeutics}

analogy is to the set of key codes needed to open various gates: different molecular interactions at the drug binding site could trigger specific conformational changes within the target MPC(s), each with a distinctive consequent change in composition and action. Continued drug advancement and further study of the transient target complex may resolve this and other issues at the boundary of current experimental tractability. Regardless, the present methods provide critical new tools to better define and characterize the common and distinctive essential host factors of each viral family and address pressing current public health problems.

\section{A Molecular basis for homeostasis}

Physiology is generally recognized as working to maintain homeostasis via feedback at allosteric sites $^{60}$. Disease occurs due to, and/or manifests as, a deviation from homeostasis. The drugs of today generally target active sites and therefore often do not restore homeostasis. Rather their efficacy, while often limited, is primarily due to disruption of disease pathophysiology, without necessarily restoring homeostasis. In the present study, infection by both CoV and FLUV was substantially restored to the uninfected state as measured by the protein composition of the target MPC $24 \mathrm{hrs}$ after drug treatment. This is consistent with the hypothesis that these compounds either re-establish homeostasis or work in concert with endogenous feedback loops at multiple levels that do so ${ }^{61}$. Further work is needed to fully explore this concept, but the demonstration of allostery involving MPCs ${ }^{60}$ and involvement of multi-functional proteins such as VCP/p97 and 14-3-3, suggest its relevance.

\section{An important unmet therapeutic need}

Apart from the intellectual interest of a relatively poorly understood dimension of catalysis with profound implications for MPC formation, homeostasis, and a new perspective on gene expression, are more immediate and practical concerns. We have identified an advanced analog, PAV-104, validated in human bronchial epithelial cells cultured to ALI, to have efficacy 


\section{Host-targeted Pan-respiratory Antiviral Therapeutics}

against SARS-CoV-2 ${ }^{62}$ ( Figure 7), with a wide margin of safety in rat 7-day toxicology (Figure 8). The path from clinical candidate nomination, through IND-enabling studies, IND filing and human clinical trials of a small molecule is a straightforward one made all the more compelling by data suggesting a substantial barrier to resistance development (Table 3). Recent data on a structurally unrelated assembly modulator identified in the manner described here, but for Retroviridae $^{17}$ demonstrated no significant resistance development after 37 cycles of selection. This suggests that the barrier to resistance development may be a general property of assembly modulators and may be substantial.

Host-targeted pan-respiratory assembly modulators such as PAV-104 are predicted to be active against not only seasonal and sporadic respiratory viral disease, but also feared pandemic strains and emerging or engineered viral threats. In this regard, advancement of these compounds may provide a hedge against unpredictable setbacks in vaccine development including the emergence of resistant strains that may undermine other therapeutic strategies, or for individuals at higher risk of adverse reactions to mainstay efforts. It is likely that the current pandemic will be followed in an unpredictable time frame by other viral pandemics, including influenza. A single drug active against everything from the common cold to pandemic strains, regardless of viral family by virtue of targeting the host, without significant resistance development liability, would be an important addition to the worldwide public health armamentarium. The demonstration of efficacy in both mild and severe disease in the early compound pig efficacy trial (Figure 3) is both reassuring and consistent with the hypothesis that targeting the host through assembly modulation is a way to restore homeostasis including innate immune function, as suggested by restoration to the assembly machine of p62/SQSTM1 that was substantially lost upon viral infection. Non-toxicity to the host is likely achieved through driving structure-activity relationship to aberrant assembly machine selectivity, as suggested by Figure 11B. 


\section{Host-targeted Pan-respiratory Antiviral Therapeutics}

Finally, it should be noted that one drug targeting the host in ways that are potently antiviral but avoid host toxicity makes possible a new respiratory anti-viral strategy. Upper respiratory infection is generally accepted to progress to lower respiratory tract disease in the subset of patients who become seriously ill from respiratory viruses. Previously, due to the diversity of viral families that cause respiratory viral disease, anti-viral compounds, e.g. Oseltamivir, were not indicated until the causative virus had been identified. Assembly modulators are shown here to be active against all of the major respiratory viral families, be they RNA or DNA viruses, enveloped or not. Thus, it becomes possible to initiate treatment early, at the onset of upper respiratory tract viral symptoms, to prevent progression to the lower respiratory tract and thereby achieve optimal benefit in shortening the duration and severity of illness.

\section{Materials and methods}

Materials. Materials were purchased from Sigma Chemical Co. or Thermo Fisher, unless otherwise noted. Selected antibodies were purchased from Bethyl Laboratories, Inc (rabbit polyclonal affinity purified antibody to VCP/p97, catalog number A300-588A-T), Abcam (mouse monoclonal antibody to human p62, catalog number ab56416), Santa Cruz (rabbit polyclonal pan 14-3-3 antibody catalog number SC-1657), LSBio (rabbit polyclonal antibody to CAPN2, catalog number LS-C400613).

Cell-free protein synthesis and assembly. Coding regions of interest (FLUV N, M, PA, PB1, and PB2, and SARS-CoV-2 np and M) were engineered behind the SP6 bacteriophage promoter and the Xenopus globin $5^{\prime} \mathrm{UTR}^{63}$. DNA was amplified by PCR and then transcribed in vitro to generate mRNA encoding each full-length protein. Translations were carried out in 


\section{Host-targeted Pan-respiratory Antiviral Therapeutics}

energy-supplemented wheat germ (WG) extracts containing ${ }^{35} \mathrm{~S}$ methionine and the other nonradiolabeled amino acids, as previously described, but at 5\% WG extract. After incubation at 26 ${ }^{\circ} \mathrm{C}$ for 90 minutes, puromycin was added to $1 \mathrm{mM}$ to terminate protein synthesis and aliquots incubated at $34{ }^{\circ} \mathrm{C}$ for 90 or 180 minutes to drive assembly. Samples were adjusted to $1 \%$ Triton X-100 and applied to sucrose step gradients.

Sucrose step gradients (ssg). To form gradients, $10 \%, 15 \%, 40 \%, 50 \%, 60 \%, 70 \%$, and $85 \%$ w/v sucrose solutions were prepared with water and then each was diluted 1/10 with a 10x stock of column buffer (50 mM Hepes, 100 mM KAc, 5 mM MgAc, 4 mM TGA) containing TritonX-100 to $1 \% .2 \mathrm{~mL}$ step gradients containing equivalent layers of each diluted sucrose solution were prepared and allowed to diffuse for 1 hour at room temperature, then chilled. Gradients were loaded with $\sim 100 \mu \mathrm{L}$ of either CFPSA product or cell lysate $(\sim 100 \mu \mathrm{g}$ of total protein), and subjected to velocity sedimentation in a Beckman TLS-55 swinging bucket rotor at 55k rpm for $50 \mathrm{~min}$ at $4{ }^{\circ} \mathrm{C}$. Gradients were fractionated from top to bottom in ten $200 \mu \mathrm{L}$ fractions, with $85 \%$ sucrose and pelleted material in an $11^{\text {th }}$ fraction adjusted to $200 \mu \mathrm{L}$ volume. Aliquots of each fraction were analyzed by polyacrylamide gel electrophoresis in sodium dodecyl sulfate (SDSPAGE). Gels were dried, scanned, and radiolabelled NP and M protein bands quantified using a Cytiva Typhoon phosphoimager and software and presented as a percent of total.

lodixanol gradient (idxg) analysis. Fraction 10 and 11 from CFPSA followed by ssg were analyzed by idxg. At $4{ }^{\circ} \mathrm{C}, 75 \mu \mathrm{L}$ of ssg fractions were added to $3 \mathrm{~mL}$ of $37.4 \%$ iodixanol, $0.2 \%$ triton column buffer mixed to homogeneity, then spun at 50k rpm for 4 hours in a Beckman TLS55 rotor. Twenty $150 \mu \mathrm{L}$ fractions were taken, a portion of each used to determine the refractive index by manual refractometry and another portion of which was analyzed by SDS-PAGE.

SDS/PAGE. SDS/PAGE was carried out as previously described ${ }^{8}$. 


\section{Host-targeted Pan-respiratory Antiviral Therapeutics}

Moderate-throughput small molecule screening. Moderate-throughput small molecule screening was carried out in a 384-well plate format by translation of eGFP and FLUV NP and M mRNA in the presence of small molecules from the Prosetta compound collection. Reactions were run at $26^{\circ} \mathrm{C}$ for $1-2$ hours for synthesis, followed by assembly at $34^{\circ} \mathrm{C}$ for 2 hours. eGFP fluorescent readout was measured at $488 / 515 \mathrm{~nm}$ (excitation/emission) to assess protein synthesis. Assembly products were captured on a second 384-well plate precoated with affinitypurified FLUV NP antibody. Plates were washed with PBS containing 1\% Triton X-100, decorated with biotinylated affinity-purified FLUV NP antibody, washed, detected by NeutraAvidin HRP, washed again, and then incubated with a fluorogenic HRP substrate Quanta Blue for 1 hour. FLUV assembly fluorescent readout was measured at 330/425 nm (excitation/emission). Relevant reagents were obtained from Pierce Protein Research Products. Using the means and standard deviations of the positive and negative controls, the $\mathrm{z}$ factor for the Flu plate screen is calculated using the formula Z-factor $=1-3($ SDpositive + SDnegative)/(MEANpositive - MEANnegative). As shown in this representative plot, the Flu plate screen routinely performs with an acceptable $\mathrm{S}: \mathrm{N}$ ratio and a Z-factor of $0.5-1$.

FLUV virus production. FLUV A/WSN/33 viral stocks were prepared in MDCK.2 cells as described previously ${ }^{64}$.

FLUV antiviral assay. Inhibition of FLUV replication was assayed using infection of MDCK.2 cells. A day before the assay, MDCK.2 cells were seeded at 30,000 cells/well in complete MEM in a 96-well plate. The next day, seeded cells were washed with PBS and incubated for 1 hour with $100 \mu \mathrm{L}$ of FLUV A/WSN/33 stock diluted in VGM media containing $42 \mathrm{mM}$ HEPES, $0.125 \%$ BSA, and $1 \mu \mathrm{g} / \mathrm{mL}$ TPCK-trypsin (final MOI of 0.001). Cells were then washed with PBS and incubated in $90 \mathrm{uL}$ of complete MEM. Single compound dilutions were prepared in complete MEM at $10 x$ the desired final concentration, and $10 \mu \mathrm{L}$ of DMSO or $10 x$ compound was added 


\section{Host-targeted Pan-respiratory Antiviral Therapeutics}

to infected cells for final volume of $100 \mu \mathrm{L}$. At 24 hours post infection, media was aspirated, cells were washed with PBS, and $100 \mu \mathrm{L}$ of complete MEM was added to each well. After a 2 hour incubation, media was collected for $\mathrm{TCID}_{50}$ determination.

To determine $\mathrm{TCID}_{50}$, ten-fold serial dilutions of virus-containing supernatant were prepared and seven replicates of $11.1 \mu \mathrm{L}$ of neat and diluted stocks were added to the MDCK cells (final dilutions in the $\mathrm{TCID}_{50}$ plate ranged from $10^{-1}-10^{6}$ ). Plates were incubated at $37^{\circ} \mathrm{C}$ for 3 days, and the number of infected wells for each dilution was determined by visual inspection. The data were used to calculate $\mathrm{TCID}_{50} / \mathrm{mL}$ using the Reed and Muench method ${ }^{65}$.

SARS-CoV-2 assay in Vero cells. SARS-CoV-2 (2019-nCoV/USA-WA1/2020; MN985325.1) was received from BEl resources and propagated in Vero clone E6, Vero E6, CRL-1586. Infections were done at a multiplicity of infection (MOI) of 0.1 in serum-free Dulbecco's minimal essential medium (DMEM) for 1 hour after which the virus-containing media was decanted and replaced with DMEM supplemented with $1 \%$ heat-inactivated fetal bovine serum ${ }^{66}$. The virus was propagated for 72 hours before it was harvested and the titer determined by plaque assay on Vero and Vero E6 cells ${ }^{67}$. The viral plaques were counted and the titer was determined as $\mathrm{PFU} / \mathrm{mL}$. The Vero cells were plated at $3 \times 10^{5}$ cells/well in a 6 -well plate and incubated overnight at $37^{\circ} \mathrm{C}$. The following day the compounds were prepared into the following concentrations/well in a separate plate; $400 \mathrm{nM}, 100 \mathrm{nM}, 25 \mathrm{nM}$, and $6 \mathrm{nM}$. The cells were washed once with PBS 1X and then infected at a multiplicity of infection (MOI) of 0.01 for 1 hour after which the virus containing media was removed and the compounds were added to the cells and incubated for 72 hours at $37^{\circ} \mathrm{C}$ at $5 \% \mathrm{CO}_{2}$. The cells were then fixed and stained with crystal violet to determine plaque numbers. These were all done in duplicate and the calculations were performed using Prism8 from GraphPad. 


\section{Host-targeted Pan-respiratory Antiviral Therapeutics}

\section{SARS-CoV-2 (delta) assay in Calu-3 cells Calu-3 cells were maintained in DMEM}

supplemented with 10\% FCS/ 1\% penicillin-streptomycin. For drug screening Calu-3 cells were seeded at a density of $3 \times 10^{4}$ cells/well in 96 -well plates. At the next day, cells were preincubated with compounds for $4 \mathrm{~h}$ at $37^{\circ} \mathrm{C}$ before they were infected with SARS-CoV2-delta SL102 (EPI_ISL_4471559) at a MOI of 0.05. After 24h the viruses within $50 \mu \mathrm{l}$ of the supernatants were lysed with $200 \mu \mathrm{L}$ AVL-buffer (Qiagen) and $200 \mu \mathrm{L}$ of $100 \%$ ethanol were added for complete inactivation. The RNA of $200 \mu \mathrm{L}$ of the lysates was extracted using the EZ1 Virus Mini-Kit (Qiagen). $5 \mu \mathrm{L}$ of the eluates were then analyzed by qPCR as described ${ }^{68}$. The infection experiments were conducted with biological triplicates in a biosafety level 3 laboratory.

Cell viability assay. $3 \times 10^{4}$ Calu-3 cells/ well were seeded in 96-well plates and were treated with compounds $24 \mathrm{~h}$ later. The viability of compound treated cells was assessed after $72 \mathrm{~h}$ with CellTiter-Glo (Promega) according to the manufacturers recommendations.

SIV and BoCoV assays. MDCK Cells $(100 \mu \mathrm{L})$ at a density of $1 \times 10^{6}-1 \times 10^{7} / \mathrm{mL}$ in MEM plus $5 \%-10 \%$ FBS were seeded in 96 -well plates. Cells were incubated for 24 hours prior to infection. After medium was removed, wells were washed once with phosphate-buffered saline (PBS). Virus solution was prepared in MEM without FBS (for SIV) or with $1 \%$ FBS (for BoCoV). Virus solution $(100 \mu \mathrm{L})$ was added to each well. The plates were incubated for 1 hour after inoculation, followed by removal of the supernatant and washing once with MEM. Compounds were diluted in MEM without FBS (for SIV) or with 1\% FBS (for BoCoV). An aliquot of $100 \mu \mathrm{L}$ of diluted compound solution was added to each corresponding well. The reaction was performed in triplicate. The cells were incubated for 24 hours. The cell monolayer was inspected for cytopathic effect (CPE). The media was collected for $\mathrm{TCID}_{50}$ determination of viral titer.

To determine $\operatorname{TCID}_{50}$, supernatant of each well was collected and ten-fold serially diluted 


\section{Host-targeted Pan-respiratory Antiviral Therapeutics}

in MEM without FBS (for SIV and BRV-B) or with $2 \%$ FBS (for BHV-1) or with $1 \%$ FBS (for BoCoV), for a dilution range of $10^{-1}-10^{-8}$. An aliquot $(100 \mu \mathrm{L})$ of each diluted solution was used to infect cell monolayers in 96-well plates, in replicates of six. The plates were incubated and observed for CPE for $2-4$ days, and then the $\mathrm{TCID}_{50}$ values were determined.

Cytotoxicity assays. For each viral inhibition assay, a cytotoxicity assay was performed in parallel on uninfected cells by adding one tenth volume of AlamarBlue (Thermo Fisher, Waltham, MA; DAL1199) to the plates and mixing well. AlamarBlue-treated plates were incubated for $2-3$ hours at $37^{\circ} \mathrm{C}$ (timing was optimized for linear signal), mixed well, and read using a fluorescence plate reader at 560/590 nm (excitation/emission) (Synergy H1; BioTek Instruments, Inc.).

Cell lysate preparation for MS-MS. MRC-5 cells were grown to $80 \%$ confluence in $15 \mathrm{~cm}$ plates either uninfected or infected with influenza A/WSN/33 or BoCoV at a low MOI. 24 hours later cells were chilled, collected by scraping, washed with ice cold PBS, extracted with $10 \mathrm{mM}$ Tris $\mathrm{pH}$ 7.6, $10 \mathrm{mM} \mathrm{NaCl}, 0.1 \mathrm{mM}$ EDTA and 0.35\% Triton X-100 (termed PB buffer), and centrifuged at $10 \mathrm{k} \times \mathrm{g}$ for $10 \mathrm{~min}$. The supernatants of uninfected, FLUV-infected, and BoCoVinfected samples were collected and flash frozen for later use.

Affinity chromatography and eDRAC protocol. Drug resin was prepared by coupling compound PAV-431 to an Affi-gel resin via the pyrazole nitrogen at a concentration of $10 \mu \mathrm{M}$. Control resin was prepared by blocking the Affi-gel matrix without drug. Resins were equilibrated with column buffer (50 mM HEPES, pH 7.6, 100 mM KAc, 6 mM MgAc, 1 mM EDTA, $4 \mathrm{mM}$ TGA) prior to any DRAC experiments. $30 \mu \mathrm{L}$ of cell extract adjusted to $1 \mathrm{mM}$ ATP, GTP, CTP and UTP with $4 \mathrm{mM}$ creatine phosphate, and in some cases rabbit creatine kinase at a final concentration of $5 \mathrm{ug} / \mathrm{ml}$, was applied. The column was clamped and incubated at $22^{\circ} \mathrm{C}$ 


\section{Host-targeted Pan-respiratory Antiviral Therapeutics}

for 1 hour for binding, and then washed with 100 bed volumes of the same buffer. 100ul of column buffer containing free compound at a final concentration of $100 \mu \mathrm{M}$ to $1 \mathrm{mM}$ (approaching its maximum solubility in water) was added, adjusted to $1 \mathrm{mM} \mathrm{ATP,} \mathrm{GTP,} \mathrm{CTP} \mathrm{and}$ UTP with $4 \mathrm{mM}$ creatine phosphate, and in some cases rabbit creatine kinase at a final concentration of $5 \mathrm{ug} / \mathrm{ml}$. The column was clamped for 1 hour, and serial eluates were collected. The column was then washed with 100 bed volumes, clamped for 1 hour in $8 \mathrm{M}$ urea or $1 \%$ SDS, washed further, and equilibrated in isopropanol for storage, or discarded.

MS-MS sample preparation and analysis. Half of each sample was processed by SDS-PAGE using a $10 \%$ Bis-Tris NuPAGE gel (Invitrogen) with the MES buffer system. The mobility region was excised and processed by in-gel digestion with trypsin using a ProGest robot (Digilab) with the protocol outlined below. Washed with $25 \mathrm{mM}$ ammonium bicarbonate followed by acetonitrile. Reduced with $10 \mathrm{mM}$ dithiothreitol at $60^{\circ} \mathrm{C}$ followed by alkylation with $50 \mathrm{mM}$ iodoacetamide at room temperature. Digested with trypsin (Promega) at $37^{\circ} \mathrm{C}$ for 4 hours. Quenched with formic acid, lyophilized, and reconstituted in $0.1 \%$ trifluoroacetic acid.

Half of each digested sample was analyzed by nano LC-MS/MS with a Waters M-Class HPLC system interfaced to a ThermoFisher Fusion Lumos mass spectrometer. Peptides were loaded on a trapping column and eluted over a $75 \mu \mathrm{m}$ analytical column at $350 \mathrm{~nL} / \mathrm{min}$; both columns were packed with Luna C18 resin (Phenomenex). The mass spectrometer was operated in data-dependent mode, with the Orbitrap operating at 60,000 FWHM and 15,000 FWHM for MS and MS/MS respectively. APD was enabled and the instrument was run with a 3 s cycle for MS and MS/MS.

Data were searched using a local copy of Mascot (Matrix Science) with the following parameters: Enzyme: Trypsin/P; Database: SwissProt Human plus the custom sequences* 


\section{Host-targeted Pan-respiratory Antiviral Therapeutics}

(concatenated forward and reverse plus common contaminants); Fixed modification:

Carbamidomethyl (C)Variable modifications: Oxidation (M), Acetyl (N-term), Pyro-Glu (N-term Q), Deamidation (N/Q)Mass values: Monoisotopic; Peptide Mass Tolerance: 10 ppm; Fragment Mass Tolerance: $0.02 \mathrm{Da}$; Max Missed Cleavages: 2. The data was analyzed by label free quantitation (LFQ) methods ${ }^{69}$. LFQ intensity values of each condition were measured in triplicate and compared against each other to generate $\log _{2}$ fold change values for each protein and each combination of conditions. Proteins that were found significantly enriched by $a \log _{2}$ fold change of $>1$ and an adjusted $p$-value (accounting for multiple hypothesis testing) of $<0.05$ in the FLUV infected eDRAC eluates compared to the uninfected eluates were searched for in a list of high confidence FLUV virus-host protein interactions ${ }^{24}$ and the VirusMentha database of virus-protein interactions ${ }^{25}$. Likewise, significantly enriched and depleted proteins found in the BoCoV infected eDRAC eluate were searched for in a list of high confidence coronavirus interactors $^{70}$ and an aggregated list of coronavirus protein interactors shown experimentally ${ }^{23}$.

Additionally, the protein data set was analyzed by spectral count. After filtering a $1 \%$ protein/peptide false discovery rate requiring 2 unique peptides per protein, the data set was further adjusted by subtraction of spectral counts for specific proteins observed in the control resin. Proteins with $>5$ spectral counts were deemed significant. Tables of proteins and their spectral counts are presented comparing uninfected vs MRC-5 cells infected with FLUV A/WSN/33 or BoCoV and for each infected sample a sample that was treated 1 hour after infection with compound PAV-431 for 24 hours.

Western blotting. For western blotting, SDS/PAGE gels were transferred in Towbin buffer to polyvinylidene fluoride membrane, blocked in 1\% BSA, incubated for 1 hour at room temperature in a 1:1,000 dilution of $100 \mu \mathrm{g} / \mathrm{mL}$ affinity-purified primary lgG, washed three times in PBS with $0.1 \%$ Tween-20, and incubated for 1 hour in a 1:5,000 dilution of secondary anti- 


\section{Host-targeted Pan-respiratory Antiviral Therapeutics}

rabbit antibody coupled to alkaline phosphatase. This incubation was followed by washing to various degrees of stringency by elevation of salt, a Tris-buffered saline wash, and incubation in developer solution prepared from $100 \mu \mathrm{L}$ of $7.5 \mathrm{mg} / \mathrm{mL}$ 5-bromo-4-chloro-3-indolyl phosphate dissolved in $60 \%$ dimethyl formamide (DMF) in water and $100 \mu \mathrm{L}$ of $15 \mathrm{mg} / \mathrm{mL}$ nitro blue tetrazolium dissolved in $70 \%$ DMF in water, adjusted to $50 \mathrm{~mL}$ with $0.1 \mathrm{M}$ Tris $(\mathrm{pH} 9.5) / 0.1 \mathrm{mM}$ magnesium chloride.

Photo-crosslinking and native vs denatured streptavidin association. eDRAC columns were eluted with $100 \mathrm{uM}$ PAV-431 photocrosslinker at $22^{\circ} \mathrm{C}$. PAV-431 to a final concentration of $100 \mathrm{uM}$ was added to an aliquot of the resulting eluate for competition 30 minutes prior to UV exposure. After crosslinking, eluates were subjected to treatments that maintained proteinprotein associations (native) or which reduced and denatured all proteins (denatured). Native conditions were maintained by adjusting an aliquot of the eDRAC free drug eluate to $20 \mathrm{x}$ volume of $1 \%$ Triton-X-100 column buffer. Denaturation was achieved by adjusting an aliquot of the eDRAC free drug eluate to $1 \%$ SDS and $10 \mathrm{mM}$ DTT and heating to $100^{\circ} \mathrm{C} / 10$ minutes. The samples were then cooled, diluted $20 x$ in $1 \%$ Triton containing column buffer so the final concentration of SDS was $0.05 \%$. Streptavidin Sepharose beads were then added to both native and denatured samples and mixed for $1 \mathrm{hr}$ to capture all biotinylated proteins, with coassociated proteins in the native case and without in the denatured case, then washed $3 x$ with $1 \%$ Triton-containing column buffer and the washed beads resuspended in 20ul of SDS loading buffer and analyzed by SDS-PAGE, transferred and analyzed by WB for the presence of various co-associated proteins under native or denatured conditions. Proteins identified only by native conditions are components of the target MPC that are lost on denaturation. Proteins identified by both native and denatured conditions are direct drug-binding proteins. 


\section{Host-targeted Pan-respiratory Antiviral Therapeutics}

PEDV pig survival efficacy study. Newborn (2 - 4 days old) crossbred pigs weighing $3 \mathrm{~kg}$ were used in the study. Animals were infected with $1 \times 10^{5}$ PFU PEDV. The compounds or vehicle was administered intraperitoneal at $4 \mathrm{mg} / \mathrm{kg}$. In the pig trial, a number of different litters of newborn pigs were all infected and then randomized to control (vehicle) and compound. Compound efficacy was determined by survivability until 5 days post-infection.

RSV cotton rat study. Twenty-four female cotton rats, $\sim 5$ weeks of age, were obtained from Envigo (formerly Harlan), ear-tagged for identification purposes and allowed to acclimate for $>1$ week prior to study start. Animals were housed individually. Just before the study initiation the animals were distributed into 4 groups so that the average weights per group were similar. Throughout the study, the cotton rats were monitored for clinical symptoms of distress or ambulatory discomfort. Body weights were recorded on days $-2,0,3$ and 5 . RSV A-2 virus was originally from ATCC (VR-1540). A high titer stock that was prepared and verified to replicate in cotton rats was used for this study.

On day $0,1 \times 10^{5}$ pfu of RSV A-2 was administered in a $50 \mathrm{~mL}$ volume by an intranasal route approximately 2 hours after the AM dose of the treatment drugs. Back titration the viral stock and diluted inoculum was performed to confirm the titer of the RSV stock used for infection. All inoculations were performed while the animals were under the influence of inhalant anesthesia. Test compound and vehicle were administered by an intraperitoneal route twice daily on study days -1 through day 4 . All animals were euthanized on day 5 and the lungs were processed for determination of RSV A-2 titers. Plaque assays were performed for viral titer determination.

Primary Airway Epithelial Cell (AEC) culture. Human bronchus was harvested from 3 explanted lungs. The tissue was submerged and agitated for 1 minute in PBS with antibiotics and 


\section{Host-targeted Pan-respiratory Antiviral Therapeutics}

$5 \mathrm{mM}$ dithiothreitol to wash and remove mucus. After 3 washes, the tissue was placed in DMEM with $0.1 \%$ protease and antibiotics overnight at $4 \mathrm{C}$. The next day solution was agitated and remaining tissue removed. Cells were centrifuged at $300 \mathrm{~g} / 4 \mathrm{C}$ for 5 minutes, then cell pellet was resuspended in $0.05 \%$ trypsin-EDTA and incubated for 5 minutes at $37 \mathrm{C}$. The trypsinization reaction was neutralized with $10 \%$ FBS in DMEM, then cells were filtered through a cell strainer and centrifuged for at $300 \mathrm{~g} / 4 \mathrm{C}$ for 5 minutes. The cell pellet was resuspended in $10 \%$ FBS in DMEM and $10 \mathrm{uL}$ was stained with trypan-blue and counted on a hemocytometer. 75,000 cells were plated onto each $6 \mathrm{~mm} / 0.4 \mathrm{~mm}$ Transwell ALI insert after treatment with FNC coating mixture. $10 \%$ FBS in DMEM and ALI media were added in equal volumes to each basal compartment and cultures were incubated at $37 \mathrm{C} / 5 \% \mathrm{CO} 2$. The next day, media was removed and both compartments were washed with PBS and antibiotics. ALI media was then added to each basal compartment and changed every 3 days until cells were ready for use at day 28 .

SARS-CoV-2 infection of ALI cultured primary AECs. All studies involving SARS-CoV-2 infection of primary AECs were conducted in the Vitalant Research Institute BSL3 HighContainment Facility. SARS-CoV-2, isolate lineage P.1, was sourced from the Biodefense and Emerging Infections (BEI) Resources of the National Institute of Allergy and Infectious Diseases (NIAID). SARS-CoV-2 was amplified in VeroE6 cells engineered to overexpress TMPRSS2 (VeroE6/TMPRSS2 cells) and viral stocks were stored at $-80^{\circ} \mathrm{C}$. Prior to infection of primary AECs, medium was removed from the basal compartment. SARS-CoV-2 (diluted in ALI-culture medium, $\mathrm{MOI}=0.1)$ was added on to the apical chamber of inserts ( $250 \mathrm{ul})$ and the basal compartment (500 ul). The cultures were then incubated for 2 hours at $37^{\circ} \mathrm{C}\left(5 \% \mathrm{CO}_{2}\right)$ to allow for virus entry. Subsequently, the cells were washed and fresh ALI medium (500 ul) was added into the basal compartment. Cells were incubated at $37^{\circ} \mathrm{C}\left(5 \% \mathrm{CO}_{2}\right)$ and harvested for analysis at 36 hours postinfection. 


\section{Host-targeted Pan-respiratory Antiviral Therapeutics}

Drug validation experiments. PAV-104, PAV-431 and PAV-471 were diluted from 10mM stock solutions in DMSO to a concentration of 100 uM in DMSO. ALI medium containing drugs or DMSO (100 nM/, 1:1000 dilution) was added to the basal compartment of the ALI-cultured primary AECs, 6 hours prior to infection. ALI medium containing drugs was removed, and SARS-CoV-2 (diluted in $\mathrm{ALI}$-culture medium containing drugs $(100 \mathrm{nM}), \mathrm{MOI}=0.1)$ was added on to the apical chamber of inserts (250 ul) and the basal compartment (500 ul). After 2 hours, cells were washed and 500 ul of fresh ALI medium containing drugs (100 nM) was added to the basal compartment. Drugs were maintained in the medium for the duration of culture post infection.

Real-time quantitative PCR (RT-PCR). Total RNA was extracted from mock and SARS-CoV-2infected primary AECs with or without drug treatment lysed in Trizol (Thermo Fisher Scientific) using the chloroform-isopropanol-ethanol method. $500 \mathrm{ng}$ of RNA was reversed transcribed into cDNA in 20 uL reaction volume using RevertAid First Strand cDNA Synthesis kit (Thermo Fisher) in accordance to the manufacturer's guidelines. RT-PCR was performed for each sample using Taqman $^{\mathrm{TM}}$ Universal Master Mix II, with UNG (Thermo Fisher) on the ViiA7 Real time PCR system. Primers and probes (2019-nCoV RUO kit) for detection of the SARS-CoV-2 Nucleocapsid (N) gene were obtained from IDT.

\section{Acknowledgments}

We thank Alfredo Calayag, Lisa Tucker, Caleb Declouette, Yvonne Dickschen, and Björn Wefers for excellent technical assistance. We thank Usha F. Lingappa and David Hanzel for careful reading and improvement of the manuscript. We thank Dmitry Temnikov for IT support. We are indebted to the late Guenter Blobel for advice, inspiration, and encouragement. Funding for this work was provided by Prosetta Biosciences Inc. A.M.S. and C.K. are funded by a grant from the Deutsche Forschungsgemeinschaft (KO1679/15-1). 
bioRxiv preprint doi: https://doi.org/10.1101/2021.01.17.426875; this version posted December 13, 2021. The copyright holder for this preprint

(which was not certified by peer review) is the author/funder, who has granted bioRxiv a license to display the preprint in perpetuity. It is made available under aCC-BY-NC-ND 4.0 International license.

\section{Host-targeted Pan-respiratory Antiviral Therapeutics}

\section{Competing interest:}

VRL is CEO of Prosetta Biosciences.

\section{Abbreviations:}

Airway epithelial cells (AECs)

Bovine Coronavirus (BoCoV)

Cell-free protein synthesis and assembly (CFPSA)

Coronavirus (CoV)

Creatine Kinase (CK)

Dithiothreitol (DTT)

Drug resin affinity chromatography (DRAC)

Enzyme-linked immunoadsorption assay (ELISA)

Energy-dependent drug resin affinity chromatography (eDRAC)

Influenza virus (FLUV)

Human immunodeficiency virus (HIV)

lodixanol buoyant density gradient (idxg)

Matrix protein (M)

Nucleoprotein (NP)

Pharmacokinetics (PK)

Polyacrylamide gel electrophoresis in sodium dodecyl sulfate (SDS-PAGE)

Porcine epidemic diarrhea virus (PEDV)

Respiratory syncytial virus (RSV)

Silver stain (SS)

Sucrose step gradient (ssg)

Swine influenza virus (SIV)

Tandem mass spectrometry (MS-MS) 


\section{Host-targeted Pan-respiratory Antiviral Therapeutics}

Transitional endoplasmatic reticulum ATPase also known as Valosin-containing protein (VCP/p97)

Western blotting (WB)

\section{References}

1. Goodwin, C. M., Xu, S. \& Munger, J. Stealing the Keys to the Kitchen: Viral Manipulation of the Host Cell Metabolic Network. Trends Microbiol. 23, 789-798 (2015).

2. Ison, M. G. Antivirals and resistance: influenza virus. Curr. Opin. Virol. 1, 563-573 (2011).

3. Peck, K. M. \& Lauring, A. S. Complexities of Viral Mutation Rates. J. Virol. 92, (2018).

4. Nirenberg, M. Historical review: Deciphering the genetic code - a personal account. Trends Biochem. Sci. 29, 46-54 (2004).

5. Blobel, G. Protein targeting (Nobel lecture). Chembiochem Eur. J. Chem. Biol. 1, 86-102 (2000).

6. Lingappa, V. R. \& Lingappa, J. R. Recent insights into biological regulation from cell-free protein-synthesizing systems. Mt. Sinai J. Med. N. Y. 72, 141-160 (2005).

7. Lingappa, J. R. et al. A eukaryotic cytosolic chaperonin is associated with a high molecular weight intermediate in the assembly of hepatitis B virus capsid, a multimeric particle. J. Cell Biol. 125, 99-111 (1994).

8. Lingappa, U. F. et al. Host-rabies virus protein-protein interactions as druggable antiviral targets. Proc. Natl. Acad. Sci. 110, E861-E868 (2013).

9. Dooher, J. E. \& Lingappa, J. R. Conservation of a stepwise, energy-sensitive pathway involving HP68 for assembly of primate lentivirus capsids in cells. J. Virol. 78, 1645-1656 (2004).

10. Lingappa, J. R., Hill, R. L., Wong, M. L. \& Hegde, R. S. A multistep, ATP-dependent pathway for assembly of human immunodeficiency virus capsids in a cell-free system. $J$. Cell Biol. 136, 567-581 (1997). 


\section{Host-targeted Pan-respiratory Antiviral Therapeutics}

11. Copeland, K. et al. Protein-Protein Interactions Occurring During HIV Capsid Assembly in a Cell-free Protein Synthesizing System. Antiviral Res. 86, A22 (2010).

12. Lingappa, J. R., Newman, M. A., Klein, K. C. \& Dooher, J. E. Comparing capsid assembly of primate lentiviruses and hepatitis B virus using cell-free systems. Virology 333, 114-123 (2005).

13. Dooher, J. E., Pineda, M. J., Overbaugh, J. \& Lingappa, J. R. Characterization of virus infectivity and cell-free capsid assembly of SIVMneCL8. J. Med. Primatol. 33, 262-271 (2004).

14. Dooher, J. E. \& Lingappa, J. R. Cell-free systems for capsid assembly of primate lentiviruses from three different lineages. J. Med. Primatol. 33, 272-280 (2004).

15. Klein, K. C., Polyak, S. J. \& Lingappa, J. R. Unique features of hepatitis C virus capsid formation revealed by de novo cell-free assembly. J. Virol. 78, 9257-9269 (2004).

16. Petsch, B. et al. Discovery of Novel Small Molecule Inhibitors of Multiple Influenza Strains in Cell Culture. Antiviral Res. 86, A42 (2010).

17. Reed, J. C. et al. Identification of an Antiretroviral Small Molecule That Appears To Be a Host-Targeting Inhibitor of HIV-1 Assembly. J. Virol. 95, e00883-20 (2021).

18. Broce, S. et al. Biochemical and biophysical characterization of cell-free synthesized Rift Valley fever virus nucleoprotein capsids enables in vitro screening to identify novel antivirals. Biol. Direct 11, 25 (2016).

19. Barnes-Seeman, D. et al. Metabolically Stable tert-Butyl Replacement. ACS Med. Chem. Lett. 4, 514-516 (2013).

20. Blanco, J. C., Boukhvalova, M. S., Perez, D. R., Vogel, S. N. \& Kajon, A. Modeling Human Respiratory Viral Infections in the Cotton Rat (Sigmodon hispidus). J. Antivir. Antiretrovir. 6, 40-42 (2014).

21. Reed, J. C. et al. Identification of an Antiretroviral Small Molecule That Appears To Be a Host-Targeting Inhibitor of HIV-1 Assembly. J. Virol. 95, (2021). 


\section{Host-targeted Pan-respiratory Antiviral Therapeutics}

22. Gordon, D. E. et al. A SARS-CoV-2 protein interaction map reveals targets for drug repurposing. Nature 583, 459-468 (2020).

23. Perrin-Cocon, L. et al. The current landscape of coronavirus-host protein-protein interactions. J. Transl. Med. 18, 319 (2020).

24. Watanabe, T. et al. Influenza virus-host interactome screen as a platform for antiviral drug development. Cell Host Microbe 16, 795-805 (2014).

25. Calderone, A., Licata, L. \& Cesareni, G. VirusMentha: a new resource for virus-host protein interactions. Nucleic Acids Res. 43, D588-592 (2015).

26. Xue, L. et al. Valosin-containing protein (VCP)-Adaptor Interactions are Exceptionally Dynamic and Subject to Differential Modulation by a VCP Inhibitor. Mol. Cell. Proteomics MCP 15, 2970-2986 (2016).

27. Zhang, J. et al. Identification of NMS-873, an allosteric and specific p97 inhibitor, as a broad antiviral against both influenza A and B viruses. Eur. J. Pharm. Sci. Off. J. Eur. Fed. Pharm. Sci. 133, 86-94 (2019).

28. Deretic, V. Autophagy as an innate immunity paradigm: expanding the scope and repertoire of pattern recognition receptors. Curr. Opin. Immunol. 24, 21-31 (2012).

29. Deretic, V. \& Levine, B. Autophagy balances inflammation in innate immunity. Autophagy 14, 243-251 (2018).

30. Gu, Y. et al. Role of the Innate Cytokine Storm Induced by the Influenza A Virus. Viral Immunol. 32, 244-251 (2019).

31. Jassal, B. et al. The reactome pathway knowledgebase. Nucleic Acids Res. 48, D498-D503 (2020).

32. Pharo, E. A. et al. Host-Pathogen Responses to Pandemic Influenza H1N1pdm09 in a Human Respiratory Airway Model. Viruses 12, E679 (2020).

33. Lee, J. A. \& Berg, E. L. Neoclassic drug discovery: the case for lead generation using phenotypic and functional approaches. J. Biomol. Screen. 18, 1143-1155 (2013). 


\section{Host-targeted Pan-respiratory Antiviral Therapeutics}

34. Versteeg, H. H., Heemskerk, J. W. M., Levi, M. \& Reitsma, P. H. New fundamentals in hemostasis. Physiol. Rev. 93, 327-358 (2013).

35. Rizzino, A. \& Wuebben, E. L. Sox2/Oct4: A delicately balanced partnership in pluripotent stem cells and embryogenesis. Biochim. Biophys. Acta 1859, 780-791 (2016).

36. Karsdal, M. A. et al. The good and the bad collagens of fibrosis - Their role in signaling and organ function. Adv. Drug Deliv. Rev. 121, 43-56 (2017).

37. Hannezo, E. \& Heisenberg, C.-P. Mechanochemical Feedback Loops in Development and Disease. Cell 178, 12-25 (2019).

38. Ivan, M. \& Kaelin, W. G. The EGLN-HIF O2-Sensing System: Multiple Inputs and Feedbacks. Mol. Cell 66, 772-779 (2017).

39. Klimesch, W. EEG alpha and theta oscillations reflect cognitive and memory performance: a review and analysis. Brain Res. Brain Res. Rev. 29, 169-195 (1999).

40. Lake, D., Corrêa, S. A. L. \& Müller, J. Negative feedback regulation of the ERK1/2 MAPK pathway. Cell. Mol. Life Sci. CMLS 73, 4397-4413 (2016).

41. Fukuda, K., Kanazawa, H., Aizawa, Y., Ardell, J. L. \& Shivkumar, K. Cardiac innervation and sudden cardiac death. Circ. Res. 116, 2005-2019 (2015).

42. Heinricher, M. M. Pain Modulation and the Transition from Acute to Chronic Pain. Adv. Exp. Med. Biol. 904, 105-115 (2016).

43. Hurley, J. M., Loros, J. J. \& Dunlap, J. C. Circadian Oscillators: Around the TranscriptionTranslation Feedback Loop and on to Output. Trends Biochem. Sci. 41, 834-846 (2016).

44. Kamenova, I. et al. Co-translational assembly of mammalian nuclear multisubunit complexes. Nat. Commun. 10, 1740 (2019).

45. Panasenko, O. O. et al. Co-translational assembly of proteasome subunits in NOT1containing assemblysomes. Nat. Struct. Mol. Biol. 26, 110-120 (2019).

46. Williams, N. K. \& Dichtl, B. Co-translational control of protein complex formation: a fundamental pathway of cellular organization? Biochem. Soc. Trans. 46, 197-206 (2018). 


\section{Host-targeted Pan-respiratory Antiviral Therapeutics}

47. Pei, Z., Harrison, M. S. \& Schmitt, A. P. Parainfluenza virus $5 \mathrm{~m}$ protein interaction with host protein 14-3-3 negatively affects virus particle formation. J. Virol. 85, 2050-2059 (2011).

48. Stevers, L. M. et al. Modulators of 14-3-3 Protein-Protein Interactions. J. Med. Chem. 61, 3755-3778 (2018).

49. Gupta, S., Ylä-Anttila, P., Sandalova, T., Achour, A. \& Masucci, M. G. Interaction With 14-33 Correlates With Inactivation of the RIG-I Signalosome by Herpesvirus Ubiquitin Deconjugases. Front. Immunol. 11, 437 (2020).

50. Tugaeva, K. V. et al. The Mechanism of SARS-CoV-2 Nucleocapsid Protein Recognition by the Human 14-3-3 Proteins. J. Mol. Biol. 433, 166875 (2021).

51. Fenton, A. W. Allostery: an illustrated definition for the 'second secret of life'. Trends Biochem. Sci. 33, 420-425 (2008).

52. Jeffery, C. J. Multitalented actors inside and outside the cell: recent discoveries add to the number of moonlighting proteins. Biochem. Soc. Trans. 47, 1941-1948 (2019).

53. Newton, A. H., Cardani, A. \& Braciale, T. J. The host immune response in respiratory virus infection: balancing virus clearance and immunopathology. Semin. Immunopathol. 38, 471482 (2016).

54. anonymous. Targeting the Host-Virus Machinery. Cell 153, 727 (2013).

55. Wang, R. \& Wang, G. Protein Modification and Autophagy Activation. Adv. Exp. Med. Biol. 1206, 237-259 (2019).

56. Lingappa, V. R., Rutkowski, D. T., Hegde, R. S. \& Andersen, O. S. Conformational control through translocational regulation: a new view of secretory and membrane protein folding. BioEssays News Rev. Mol. Cell. Dev. Biol. 24, 741-748 (2002).

57. Alpert, E. et al. Multifunctionality of Prostatic Acid Phosphatase in Prostate Cancer Pathogenesis. Biosci. Rep. BSR20211646 (2021) doi:10.1042/BCJ20200944.

58. Martinez-Seidel, F., Beine-Golovchuk, O., Hsieh, Y.-C. \& Kopka, J. Systematic Review of Plant Ribosome Heterogeneity and Specialization. Front. Plant Sci. 11, 948 (2020). 


\section{Host-targeted Pan-respiratory Antiviral Therapeutics}

59. Liu, J. et al. The role of 14-3-3 proteins in cell signalling pathways and virus infection. J. Cell. Mol. Med. 25, 4173-4182 (2021).

60. Pardee, A. B. \& Reddy, G. P.-V. Beginnings of feedback inhibition, allostery, and multiprotein complexes. Gene 321, 17-23 (2003).

61. Shaban, M. S. et al. Multi-level inhibition of coronavirus replication by chemical ER stress. Nat. Commun. 12, 5536 (2021).

62. Mulay, A. et al. SARS-CoV-2 infection of primary human lung epithelium for COVID-19 modeling and drug discovery. Cell Rep. 35, 109055 (2021).

63. Krieg, P. A. \& Melton, D. A. Functional messenger RNAs are produced by SP6 in vitro transcription of cloned cDNAs. Nucleic Acids Res. 12, 7057-7070 (1984).

64. Lutz, A., Dyall, J., Olivo, P. D. \& Pekosz, A. Virus-inducible reporter genes as a tool for detecting and quantifying influenza A virus replication. J. Virol. Methods 126, 13-20 (2005).

65. Reed, L. J. \& Muench, H. A SIMPLE METHOD OF ESTIMATING FIFTY PER CENT ENDPOINTS12. Am. J. Epidemiol. 27, 493-497 (1938).

66. Harcourt, J. et al. Severe Acute Respiratory Syndrome Coronavirus 2 from Patient with Coronavirus Disease, United States. Emerg. Infect. Dis. 26, 1266-1273 (2020).

67. Zhang, Y., Wei, Y., Li, J. \& Li, J. Development and optimization of a direct plaque assay for human and avian metapneumoviruses. J. Virol. Methods 185, 61-68 (2012).

68. Ramani, A. et al. SARS-CoV-2 targets neurons of 3D human brain organoids. EMBO J. 39, e106230 (2020).

69. Shah, A. D., Goode, R. J. A., Huang, C., Powell, D. R. \& Schittenhelm, R. B. LFQ-Analyst: An Easy-To-Use Interactive Web Platform To Analyze and Visualize Label-Free Proteomics Data Preprocessed with MaxQuant. J. Proteome Res. 19, 204-211 (2020).

70. Gordon, D. E. et al. Comparative host-coronavirus protein interaction networks reveal panviral disease mechanisms. Science 370, (2020). 
bioRxiv preprint doi: https://doi.org/10.1101/2021.01.17.426875; this version posted December 13, 2021. The copyright holder for this preprint (which was not certified by peer review) is the author/funder, who has granted bioRxiv a license to display the preprint in perpetuity. It is made available under aCC-BY-NC-ND 4.0 International license.

Host-targeted Pan-respiratory Antiviral Therapeutics

Figures
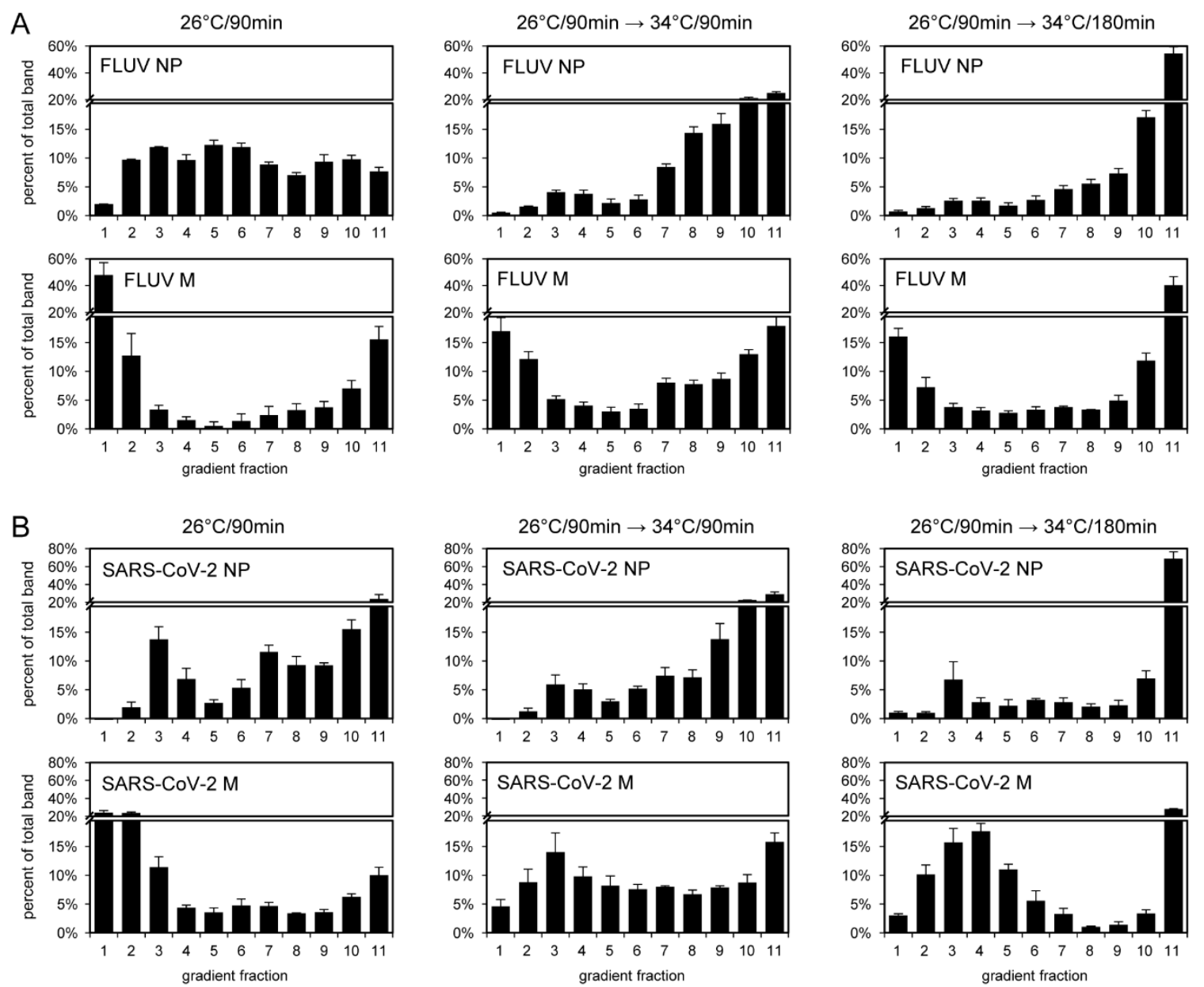

Figure 1. CFPSA of putative FLUV and SARS-CoV-2 capsids. Cell-free protein synthesis reactions were programmed with a cocktail of mRNAs encoding relevant FLUV or SARS-CoV-2 proteins. Reactions were incubated at $26{ }^{\circ} \mathrm{C}$ for protein synthesis and moved to $34{ }^{\circ} \mathrm{C}$ for assembly. Analysis of CFPSA products by ssg revealed time-dependent assembly pathways, with the progression of viral gene products to the bottom of the gradient, shown here for both FLUV (A) and SARS-CoV-2 (B). 


\section{Host-targeted Pan-respiratory Antiviral Therapeutics}

A

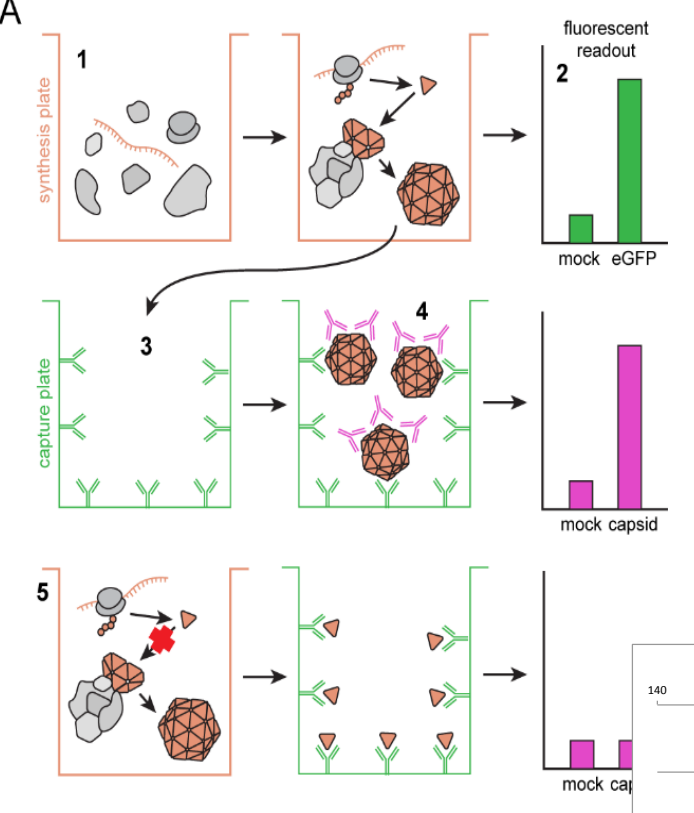

B Library of $\sim 150,000$ drug-like compounds

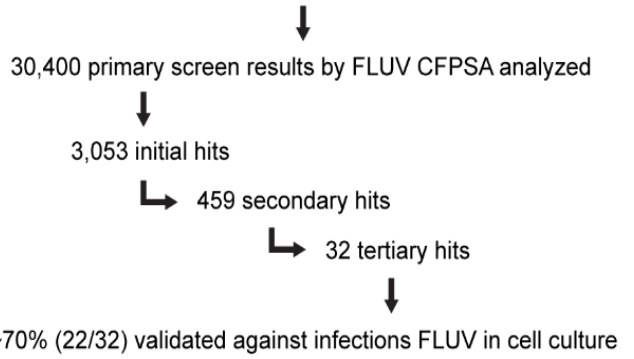

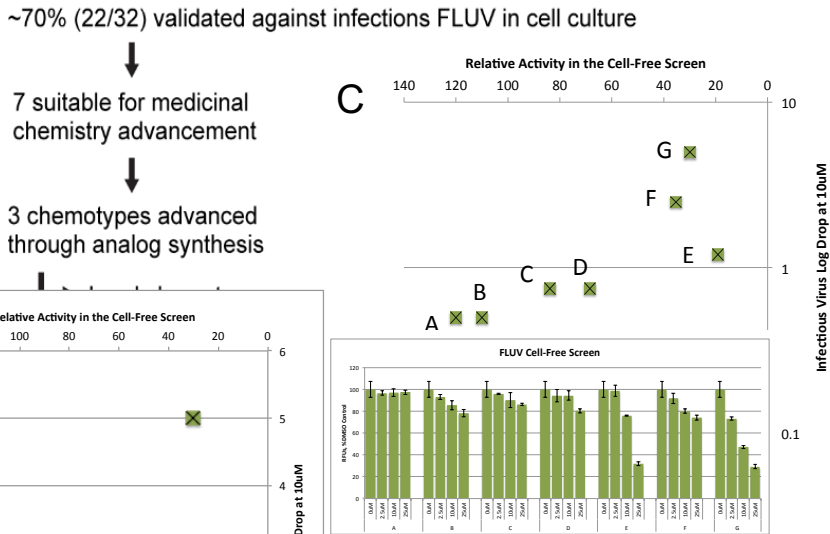

Figure 2. FLUV drug screen, results, and validation. A. Schematic of the CFPSA phenotypic drug screen indicating steps and readouts. CFPSA reactions carried out in 384-well format (1) result in synthesis of encoded FLUV proteins, with co-expression of eGFP to distinguish compounds that lower fluorescence readout due to a trivial effect on protein synthesis (2). Assembled products are transferred to a capture plate (3), which is coated with antibodies to the FLUV NP, capturing and immobilizing synthesized FLUV proteins. As a function of multimerization, unoccupied epitopes will exist on bound assembly intermediates and completed viral structures. Secondary antibodies with fluorescent tags bind those exposed epitopes (4), generating a fluorescent readout specific to multimeric assembly. Drug action that directly or indirectly block multimer formation results in a diminution of signal (5). B. Summary of FLUV screen outcome. C. Correlation between compound activity in CFPSA screen (x-axis) and activity against infectious virus in cell culture ( $y$-axis assessed by log drop in FLUV titer by $\mathrm{TCID}_{50}$ ). A-G indicate compounds representing distinct FLUV-active chemotypes with $<70 \%$ similarity by Tanimoto coefficient. The bottom panel shows the dose-dependent plots from the CFPSA screen from which relative CFPSA activity was determined. 


\section{Host-targeted Pan-respiratory Antiviral Therapeutics}

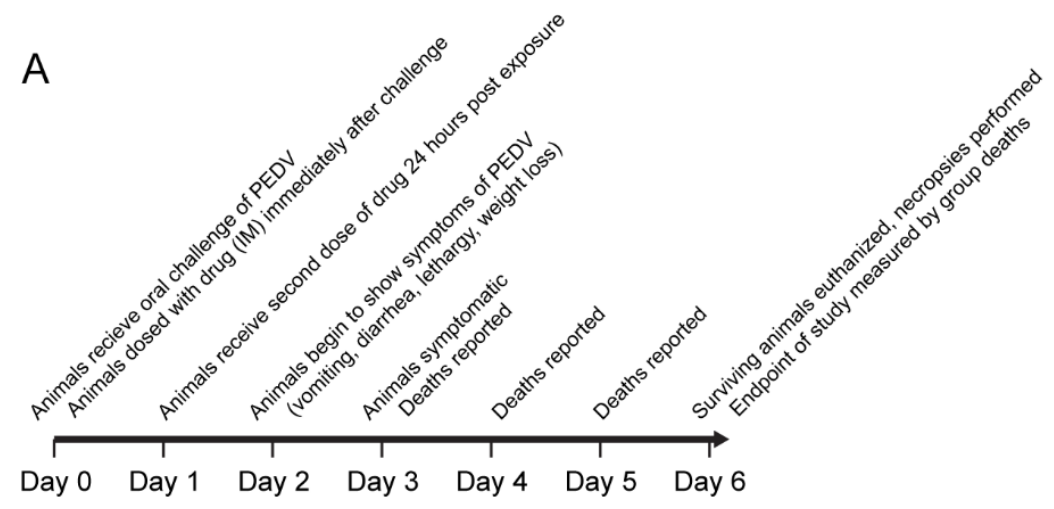

B full population

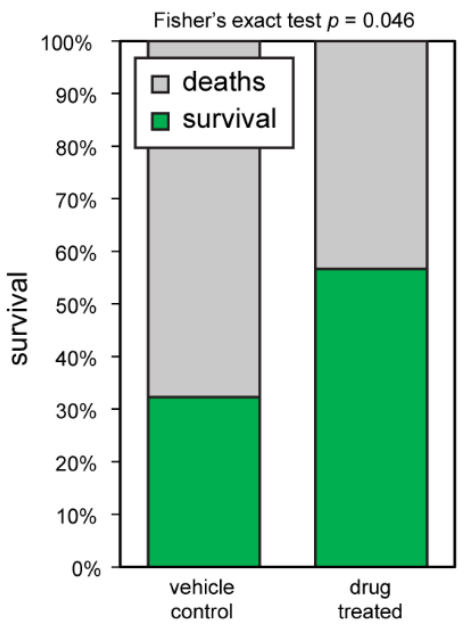

subset of litters with $100 \%$ control death, i.e., severe disease

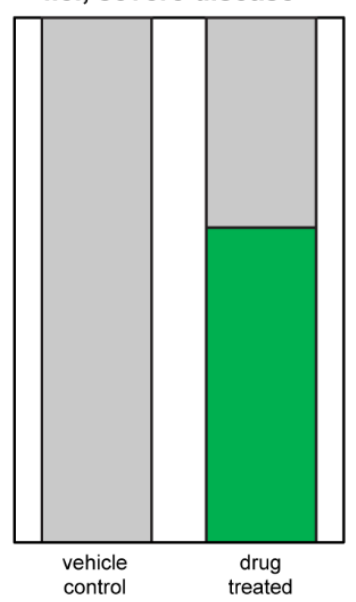

\begin{tabular}{|c|c|c|c|}
\cline { 2 - 4 } \multicolumn{1}{c|}{ C } & vehicle & PAV-835 & PAV-773 \\
\hline \% survival & $32.3 \%$ & $56.7 \%$ & $56.7 \%$ \\
\hline survivors & 10 & 17 & 17 \\
\hline deaths & 21 & 13 & 13 \\
\hline
\end{tabular}

\begin{tabular}{|c|c|c|}
\hline vehicle & PAV-835 & PAV-773 \\
\hline $0.0 \%$ & $57.1 \%$ & $66.7 \%$ \\
\hline 0 & 8 & 10 \\
\hline 15 & 7 & 5 \\
\hline
\end{tabular}

Figure 3. PEDV pig efficacy trial of early lead series compounds PAV-773 and PAV-835. A. Study timeline and observations. B. Study results. The graph on the left represents all animals in the study with percent survival shown in green. As results with PAV-773 and PAV835 were identical, they have been combined (Fisher exact test $p=0.046$ ). The graph on the right represents the subset of litters in which all control animals (treated with vehicle only) died. C. Breakdown of survival for PAV-773 and PAV-835 separately for both the total population and the severe disease subset, where $p=0.002$ and $p=0.004$, respectively. 
bioRxiv preprint doi: https://doi.org/10.1101/2021.01.17.426875; this version posted December 13, 2021. The copyright holder for this preprint (which was not certified by peer review) is the author/funder, who has granted bioRxiv a license to display the preprint in perpetuity. It is made available under aCC-BY-NC-ND 4.0 International license.

\section{Host-targeted Pan-respiratory Antiviral Therapeutics}

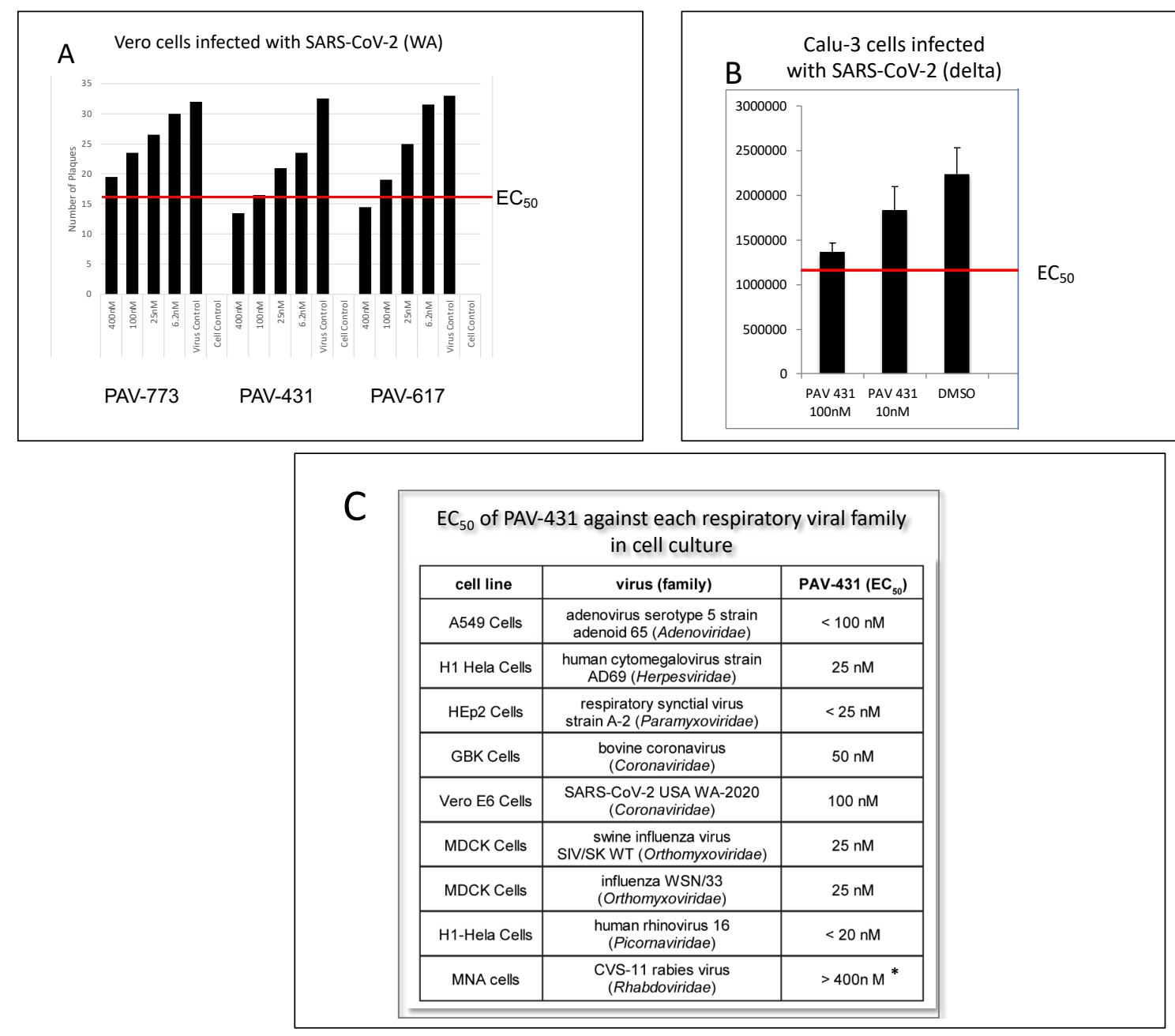

Figure 4. Pan-respiratory antiviral activity of PAV-431. A. Dose-dependent antiviral activity of two assembly modulator chemotypes (PAV-431 and PAV-617) against SARS-CoV-2 determined by plaque assay in Vero E6 cells. B. Dose-dependent antiviral activity of PAV-431 against SARSCoV-2 (delta) by low MOI (0.01) spread assay and PCR quantitation of viral load. Dose dependent antiviral activity against SARS-CoV2-delta determined by qPCR of the E-gene in Calu-3 wells. Remdesivir $(10 \mu \mathrm{M})$ was applied as technical positive control. Each column represents the average plus SEM of three biological replicates. C. Efficacy of PAV-431 against each respiratory viral family in cell culture. 


\section{Host-targeted Pan-respiratory Antiviral Therapeutics}

A

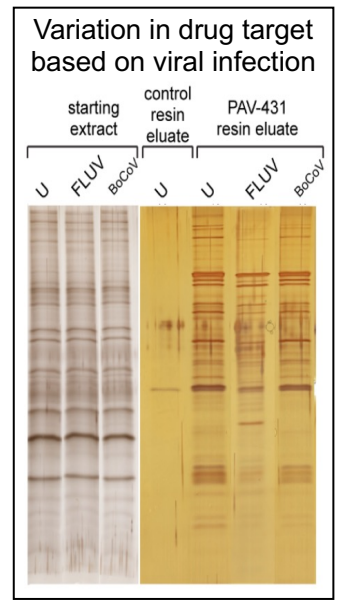

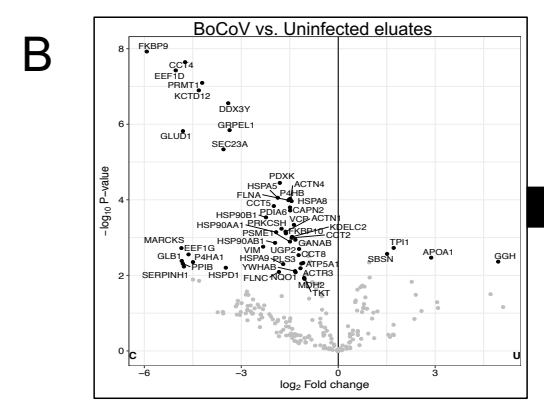
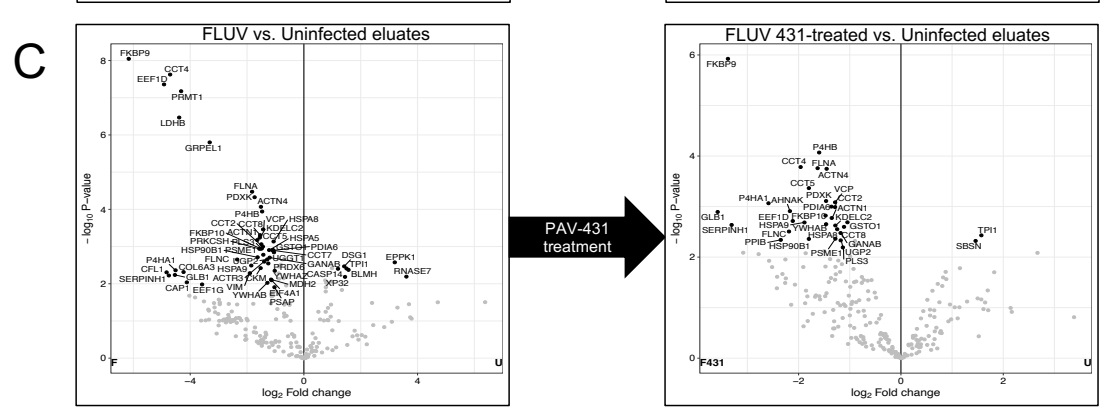

Figure 5. Normal assembly machine composition, aberrant assembly machine formation upon infection, and restoration to normal with drug treatment. Triplicate eDRAC eluates of DMSO-treated and PAV-431-treated MRC-5 cells either uninfected, FLUV-infected, or BoCoVinfected were collected and analyzed by silver stain (A) and by LC/MS-MS with volcano plots shown for BoCoV (B) and FLUV (C). Left hand plots are DMSO treated, right hand plots are PAV-431-treated. Using LFQ intensity values from MaxQuant analysis, for each experimental condition Log 2 fold change from uninfected eDRAC eluates and $p$-values were calculated and presented as volcano plots $(B, C)$. Settings for calculations were adjusted $p$-value cut off $=0.05$; Log2 fold change cut off $=1$; imputation type $=$ min; Benjamini Hochberg FDR. Control resin (lacking the drug ligand) had the same starting uninfected cell extract applied, and then washed and eluted, as was done for the drug resin. This control resin free drug eluate was analyzed by LC/MS-MS in the same manner as was done for the free drug eluate from the drug resin and was defined as the background to be subtracted from the uninfected drug resin LC/MS-MS findings. Lists of proteins (D, E) are grouped from top to bottom in terms of their known involvement in i) innate immune functions, then ii) those involved in the lifecycles of each viral family (CoV and FLUV), and iii) all others. Yellow indicates protein abundance as observed in the uninfected extract eDRAC free drug eluates $(-1<\log 2$ fold change $>1$, p-value $<0.05)$. Green refers to proteins significantly enriched in the infected eDRAC free drug eluate (log2 fold change $>1, p$-value $<0.05)$. Red refers to proteins depleted in the infected eDRAC free drug eluate (log2 fold change $<-1$, p-value $<0.05$ ). 
bioRxiv preprint doi: https://doi.org/10.1101/2021.01.17.426875; this version posted December 13, 2021. The copyright holder for this preprint (which was not certified by peer review) is the author/funder, who has granted bioRxiv a license to display the preprint in perpetuity. It is made available under aCC-BY-NC-ND 4.0 International license.

\section{Host-targeted Pan-respiratory Antiviral Therapeutics}
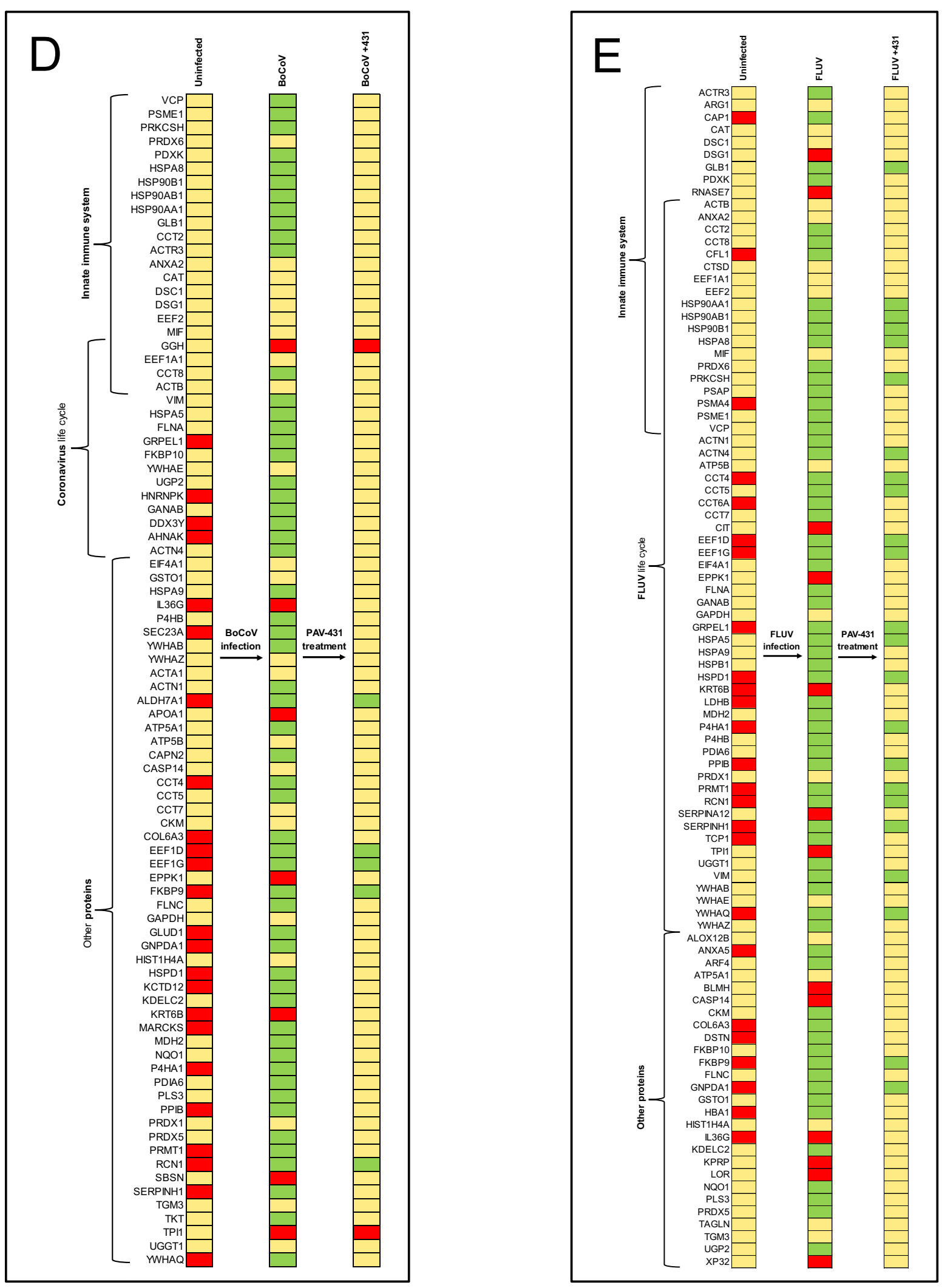

Figure 5 D, E (see legend on previous page) 
bioRxiv preprint doi: https://doi.org/10.1101/2021.01.17.426875; this version posted December 13, 2021. The copyright holder for this preprint (which was not certified by peer review) is the author/funder, who has granted bioRxiv a license to display the preprint in perpetuity. It is made available under aCC-BY-NC-ND 4.0 International license.

\section{Host-targeted Pan-respiratory Antiviral Therapeutics}
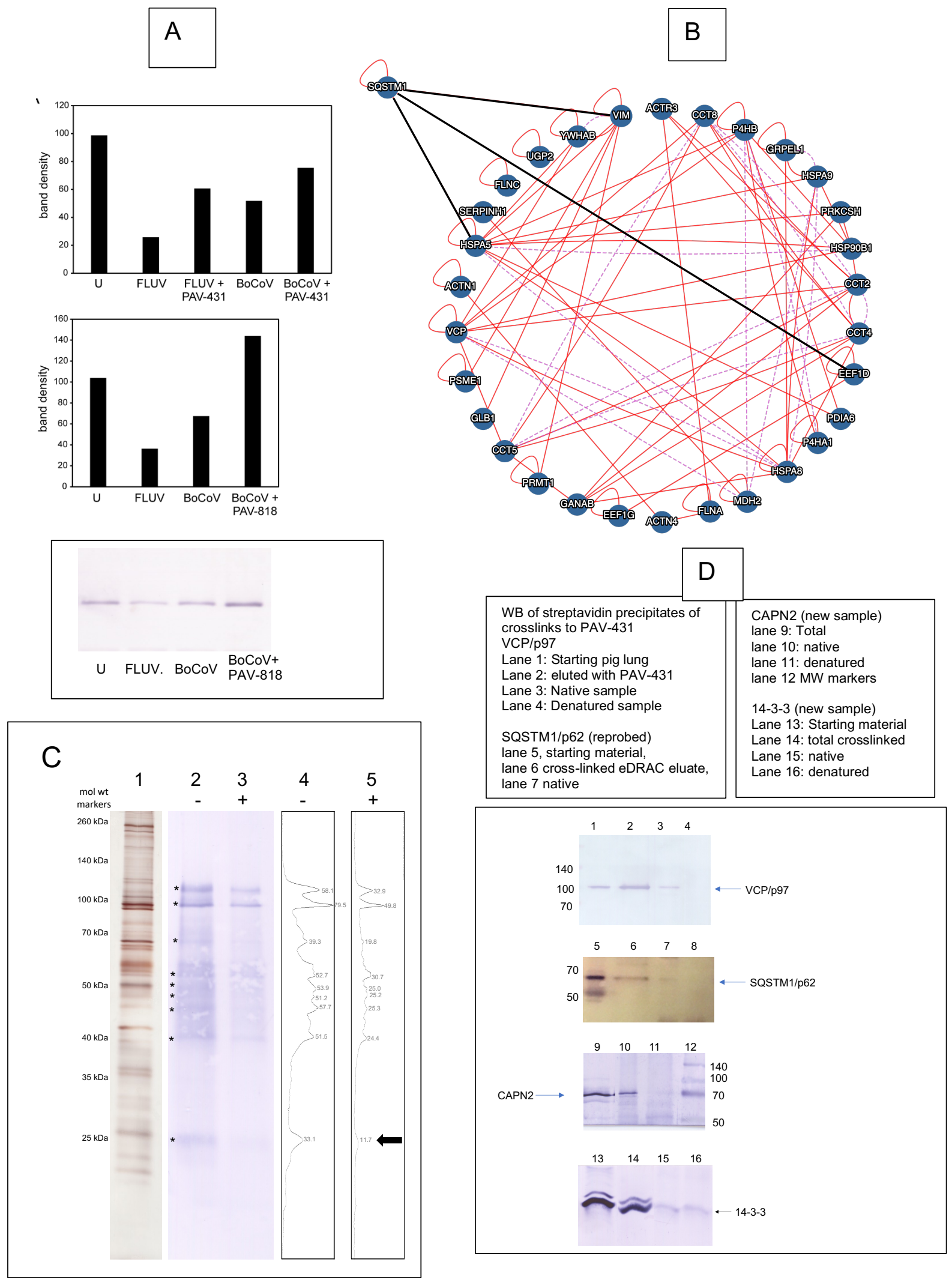

Figure 6. Significance of key proteins in the eDRAC eluate. A. MRC-5 cells or HRT-18G cells either uninfected $(U)$, or infected with FLUV or BoCoV, or infected and subsequently treated with PAV-431 or PAV-818, were extracted with PB buffer, and the $10 \mathrm{kxg} / 10 \mathrm{~min}$ 

available under aCC-BY-NC-ND 4.0 International license.

Host-targeted Pan-respiratory Antiviral Therapeutics

supernatant adjusted to $1 \times \mathrm{CB}$ and applied to PAV-431 resin according to the eDRAC protocol. Free drug eluate was analyzed by SDS-PAGE and WB for SQSMT1/p62. Shown are quantified p62 bands seen by WB for MRC-5 cells (above) and HRT18G cells (below), with the actual WB shown for HRT18G below. Both FLUV and BoCoV infection resulted in a striking diminution of SQSMT1/p62 in the eDRAC eluate. B. Comparison of protein components of eDRAC eluates and host interactomes implicated in the lifecycles of FLUV and CoV, along with corresponding databases that implicate proteins found by eDRAC in the PAV-431 resin eluate, in various immune functions. SQSTM1/p62 is the only protein shown that was found by WB, all others by MS-MS. Note that SQSTM1/p62, found by WB, is known to interact directly with three of the proteins found in the eDRAC eluate by MS-MS (black lines). Many of the others interact with one another (red lines). C. Lane 1 is a silver stain of the starting pig lung eDRAC eluate that was subjected to photo-crosslinking with the PAV-431 diazarine and biotin-containing analog. Strepavidin blot of pig lung eDRAC eluate in the absence (-) and presence (+) of free drug competitor followed by photocrosslinking as described. Lane 4 shows quantitation of bands in lane 2 (- free drug). Lane 5 shows quantitation of Lane 3 (+ free drug). Only the $24 \mathrm{kDa}$ band (black arrow) shows substantially $>2 x$ diminution of crosslinked adducts in presence of free drug. D. co-IP under native vs denaturing conditions of crosslinked eDRAC eluate. Starting pig lung $10 \mathrm{kxg}$ supernatant was blotted for VCP/p97 (lane 1). Uninfected pig lung 10kxg supernatant was applied to eDRAC column, washed, and eluted with PAV-431crosslinker and blotted for VCP/p97 (lane 2). An aliquot of the crosslinked products was adjusted to $1 \%$ SDS and $10 \mathrm{mM}$ DTT and heated at $100^{\circ} \mathrm{C} / 10$ minutes, then diluted $20 x$ with column buffer containing $1 \%$ triton $x-100$ (denatured sample). An equal sample was just diluted with column buffer containing $1 \%$ triton (native sample). Streptavidin-sepharose was used to isolate crosslinked adducts from the native vs denatured samples, and the washed beads analyzed by SDS-PAGE and WB with antisera to VCP/p97 (lane 3, native and lane 4, denatured). WB was reprobed for SQSTM1/p62 (lane 5, starting material, lane 6 cross-linked eDRAC eluate, lane 7 is isolated streptavidin Sepharose bound material native, reprobed with antibody to SQSTM1/p62, lane 8 is isolated streptavidin Sepharose bound material denatured, reprobed with antibody to SQSTM1/pt62. Another identical set of samples was prepared and blotted instead for CAPN2. Total crosslinked products, lane 9; native, lane 10, denatured, lane 11. Molecular weight markers are indicated in lane 12. Another identical set of samples was prepared and blotted instead for 14-3-3. Starting material, lane 13; total crosslinked products, lane 14; native, lane 15, denatured, lane 16. As can be seen, of the four WBs shown only that for 14-3-3 has reactivity in the material precipitated by streptavidin Sepharose after denaturing conditions, indicating that 14-3-3 is a direct nearest neighbor protein to the biotinylated drug analog with covalently attached biotin following crosslinking. 
bioRxiv preprint doi: https://doi.org/10.1101/2021.01.17.426875; this version posted December 13, 2021. The copyright holder for this preprint (which was not certified by peer review) is the author/funder, who has granted bioRxiv a license to display the preprint in perpetuity. It is made available under aCC-BY-NC-ND 4.0 International license.

Host-targeted Pan-respiratory Antiviral Therapeutics

Figure 7

A

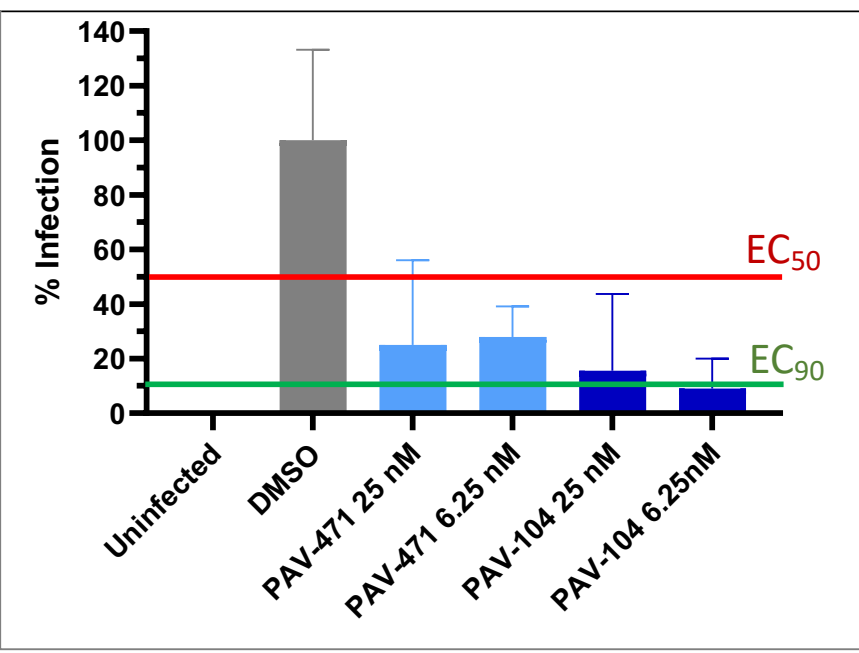

B
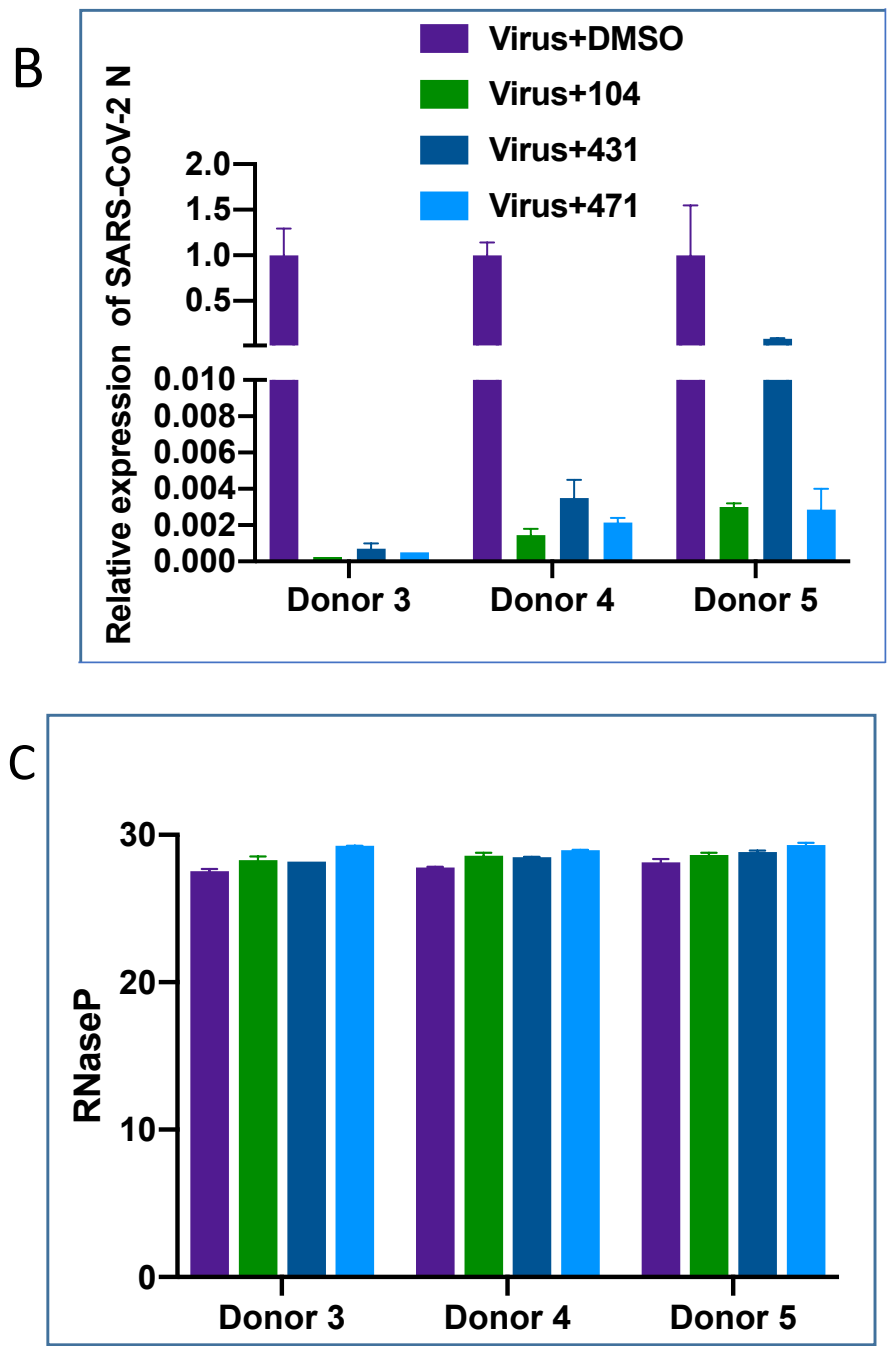

Figure 7. Pre-treatment with PAV-104, PAV-431 and PAV-471 of primary airway epithelial cells (grown to an air-liquid interface), inhibit SARS-CoV-2 replication. A. Efficacy of compound PAV-471 and PAV-104 against human CoV229E in MRC5 cells infected at $\mathrm{MOI} 0.01$ and treated $1 \mathrm{hr}$ later. B. Primary AECs were pretreated with the indicated compounds at the concentration of $100 \mathrm{nM}$ for 6 hours at $37^{\circ} \mathrm{C}$ and then incubated with SARS-CoV-2 (lineage P.1, MOI=0.1) for 2 hours. Unbound virus particles were removed, and fresh ALI medium containing drugs was added. Drugs were maintained in the medium for the duration of culture post infection (36 hours). Virus replication was analyzed using RT-PCR measurement of the SARS-CoV-2 N gene. C. Ct value of RNase $P$ is shown comparing DMSO to drug treatment, as one metric demonstrating lack of drug toxicity. 
bioRxiv preprint doi: https://doi.org/10.1101/2021.01.17.426875; this version posted December 13, 2021. The copyright holder for this preprint (which was not certified by peer review) is the author/funder, who has granted bioRxiv a license to display the preprint in perpetuity. It is made available under aCC-BY-NC-ND 4.0 International license.

\section{Host-targeted Pan-respiratory Antiviral Therapeutics}

Figure 8. A PK properties of lead series compounds

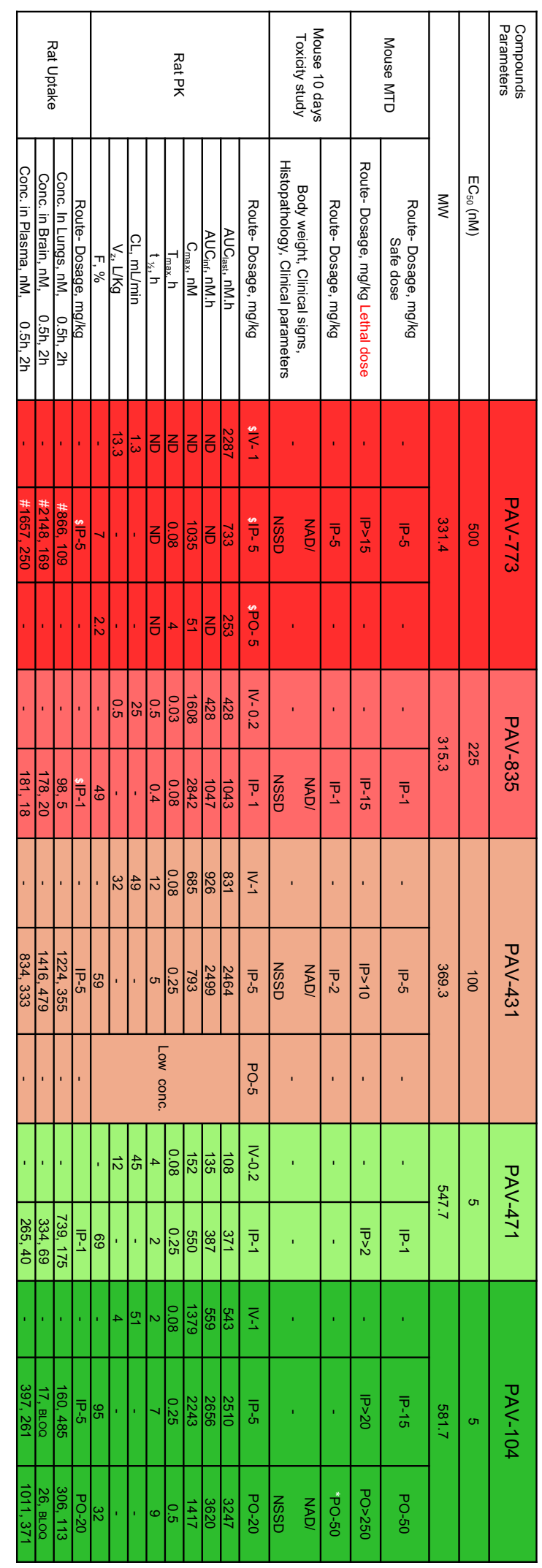


Host-targeted Pan-respiratory Antiviral Therapeutics

Figure 8B. Plasma and lung exposure of PAV-104 on the $7^{\text {th }}$ day after daily oral dosing at $50 \mathrm{mg} / \mathrm{kg}$ for 7 days.

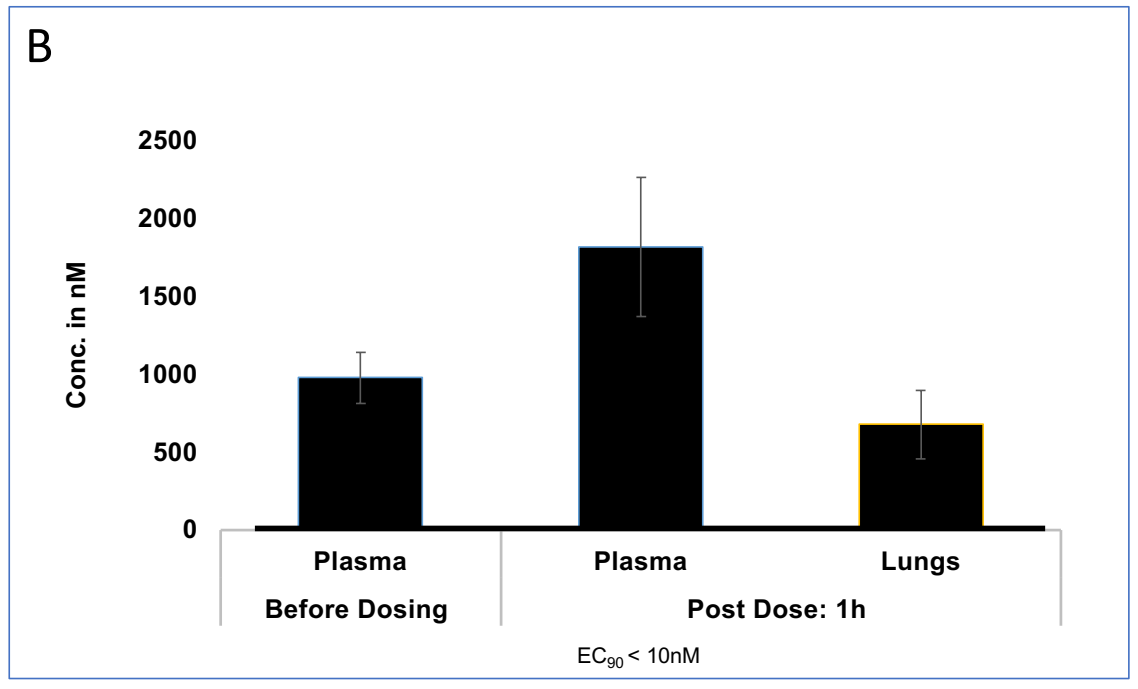

Figure 8. Pharmacokinetic and toxicological assessment of the lead series.

A: MTD was evaluated in BALB/c mice. Doses and routes were fixed as mentioned in the table. Animals were observed for toxic signs up to $48 \mathrm{~h}$. Acute repeat dose toxicity was evaluated in $\mathrm{BALB} / \mathrm{c}$ mice with daily dose as mentioned in the table. Doses and routes were fixed as mentioned in the table. Body weight measurements were taken daily before dosing, and clinical signs were observed. At the end of the study, animals were sacrificed; clinical signs, clinical parameters and histopathology were determined. PK was evaluated in Sprague Dawley rats. Doses and routes were fixed as mentioned in the table. Blood was drawn through cannulation at regular time intervals. Compound levels were estimated by LC-MS and Pharmacokinetic parameters were determined using WinNonlin software. Uptake study was evaluated in Sprague Dawley (SD) rats. Dose and route were fixed as mentioned in the table. Animals were sacrificed at the said time points and organs were collected. Organs were homogenized in known volume of buffer and compound levels were estimated by LC-MS analysis. EC, effective concentration; MW, molecular weight; IV, intravenous; IP, intraperitoneal; PO, per oral; PK, pharmacokinetics; $A \cup C_{\text {last }}$, area under the curve from time zero to the last quantifiable concentration; $A U C_{\text {inf, }}$ area under the curve vs. time curve extrapolated to infinity; $C_{\max }$, peak plasma concentration; $T_{\max }$, time of peak concentration observed; $t_{1 / 2}$, terminal half-life; $C L$, steady-state clearance; $V_{z}$, volume of distribution; F, Fraction bioavailability; h, hour; NAD, no abnormality detected; NSSD, no significant statistical difference; BLOQ, below level of quantification; ND, not determined.

B: Acute repeat dose toxicity was evaluated in Sprague Dawley (SD) rats for 7 days with daily dose of PO-50 mg/kg. Body weight measurements were taken daily before dosing, and clinical signs were observed. At the end of the study, animals were sacrificed; clinical signs, trough levels and clinical parameters were determined. 


\section{Host-targeted Pan-respiratory Antiviral Therapeutics}

A
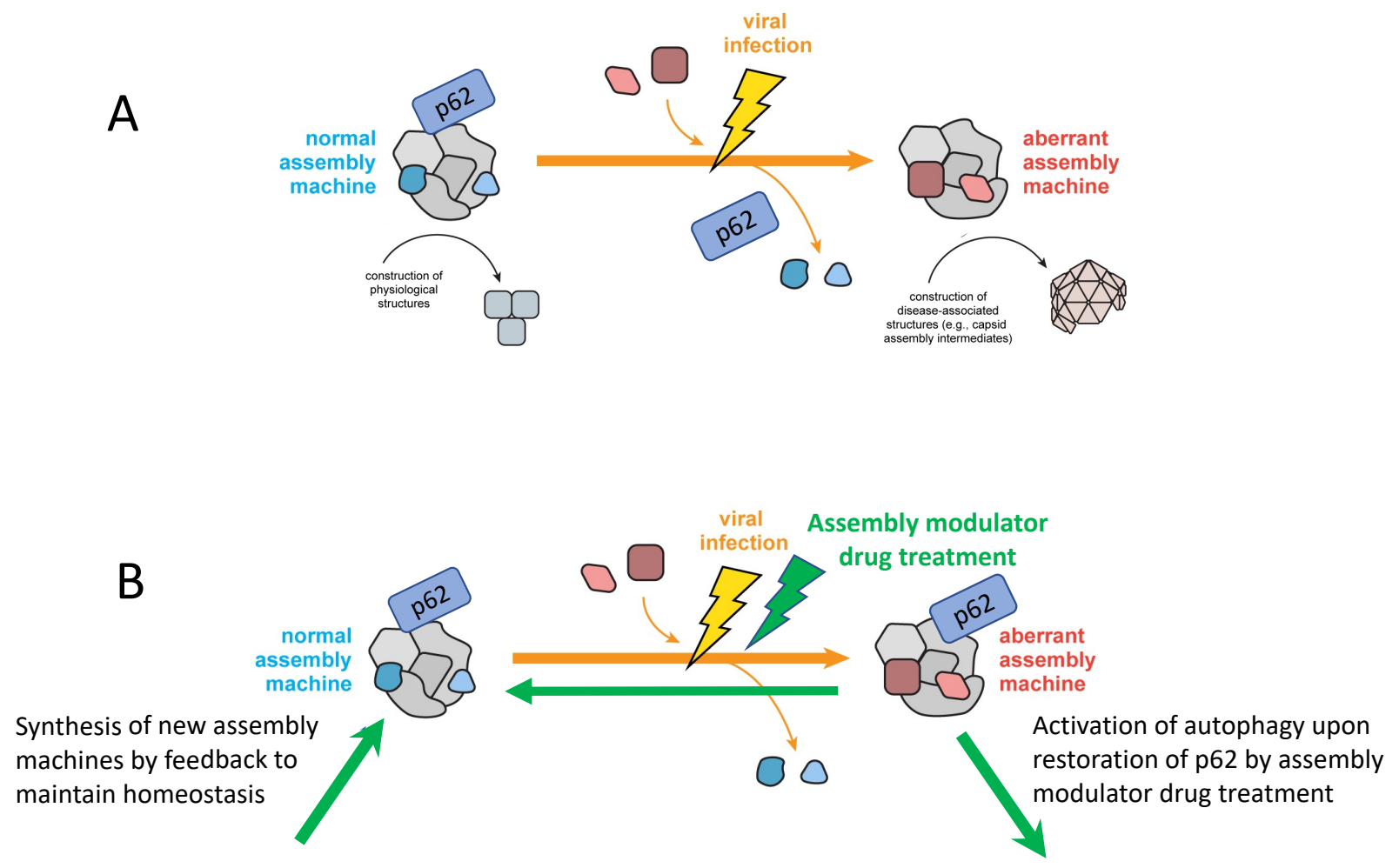

Figure 9. Cartoon summarizing our working hypothesis on assembly modulation therapeutics, based on the studies presented here. A. Normal assembly machines (top left) comprise transient MPCs that come together to carry out various events involved in the construction of physiological structures providing a crucial molecular basis for homeostasis. Certain insults, including viral infection (yellow lightening bolt), are able to disturb assembly machine composition. Viruses have evolved to facilitate the changes in assembly machines that meet their needs, presumably through signaling pathway manipulation. This causes formation of an aberrant assembly machine that does something it is not supposed to do (e.g. building a viral capsid) and perhaps fails to do something it is supposed to do (e.g. inform innate immunity that the cell is under viral attack), due to loss of p62/SQSTM1 from the assembly machine. The former action is reflected as viral propagation and the latter action is reflected in the failure of autophagic innate immune defense. Both consequences manifest as disease and their molecular basis is the normal to aberrant change in assembly machine composition. B. Treatment with assembly modulators results in restoration of the normal assembly machine either through direct action (leftward pointing green arrow) e.g. on an allosteric site, or through a more circuitous route in which early restoration of p62/SQSTM1 allows activation of autophagic destruction of the aberrant assembly machine and feedback repopulation of normal assembly machines (green arrow on the left and right). Note that infected cells contain both normal and aberrant assembly machines, while uninfected cells contain only normal assembly machines. 

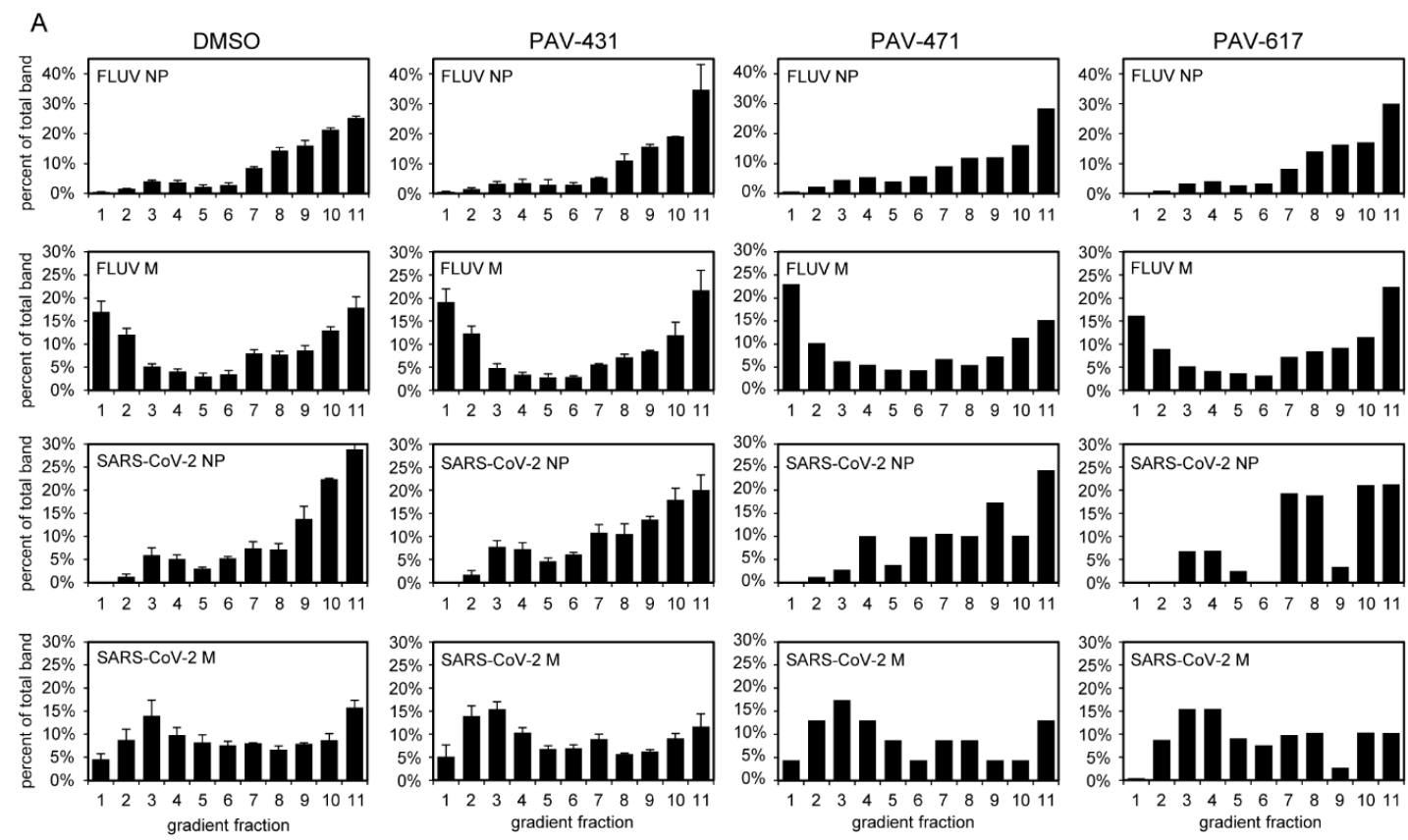

\begin{tabular}{|c|c|c|c|c|}
\hline & DMSO & PAV-431 & PAV-471 & PAV-617 \\
\hline $\mathrm{f} \mathrm{3+4}$ & 23 & 25.5 & 30.5 & 30.5 \\
\hline $\mathrm{f} 9$ & 8 & 6.25 & 4.25 & 2.75 \\
\hline
\end{tabular}
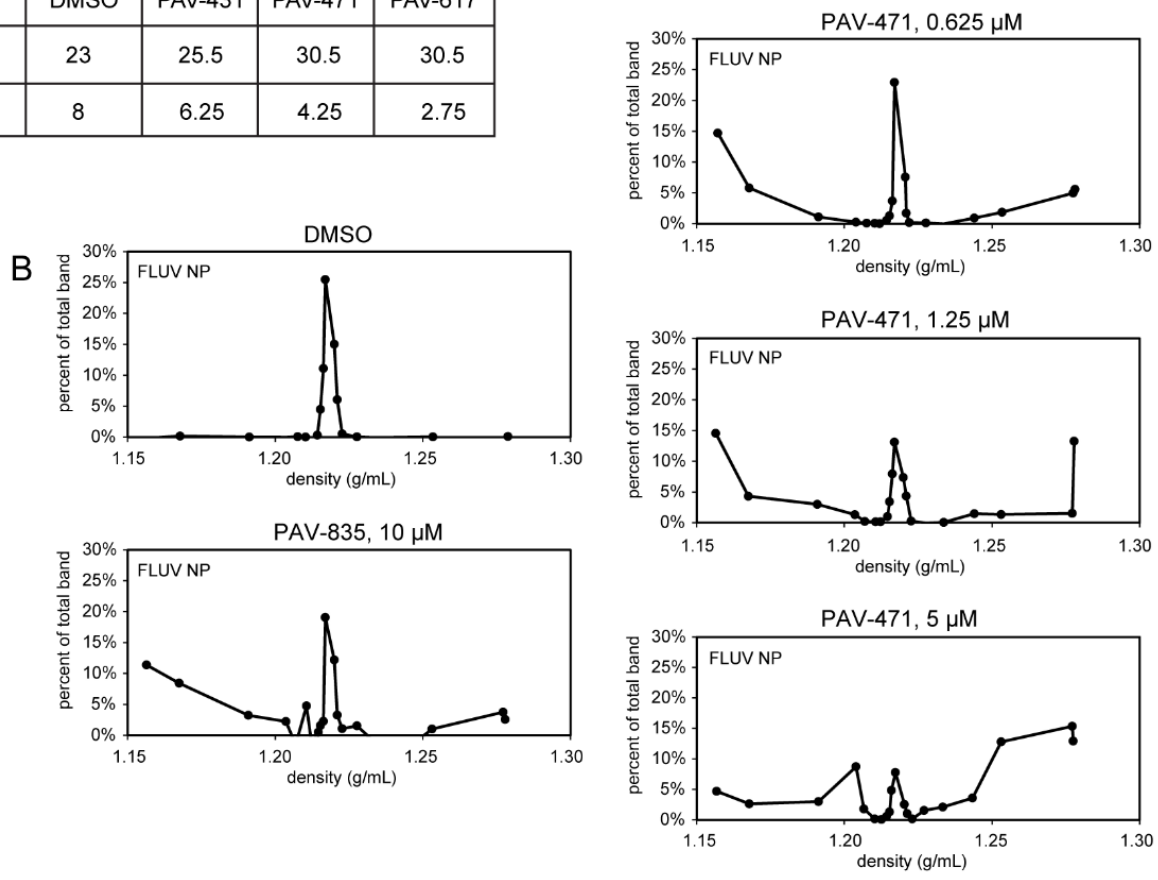

Figure 10. Assembly modulator drug effects on FLUV and SARS-CoV-2 assembly by CFPSA. A. CFPSA with FLUV or SARS-CoV-2 mRNAs as previously described for Figure 1 were carried out in the presence of either vehicle alone (DMSO) or $10 \mu \mathrm{M}$ PAV-431 or backup chemotypes PAV-471 or PAV-617, and analyzed by ssg. The inset table highlights the compound effects on SARS-CoV-2 by indicating the percent of total SARS-Cov-2 M protein found in ssg fractions 3 and 4 vs. fraction 9. B. lodixanol gradient (idxg) analysis of FLUV ssg fractions 10 and 11 , showing a dose-dependent change from the density of $1.218 \mathrm{~g} / \mathrm{mL}$ observed for assembly to material that migrates at both higher and lower densities upon compound treatment. 
bioRxiv preprint doi: https://doi.org/10.1101/2021.01.17.426875; this version posted December 13,2021 . The copyright holder for this preprint (which was not certified by peer review) is the author/funder, who has granted bioRxiv a license to display the preprint in perpetuity. It is made available under aCC-BY-NC-ND 4.0 International license.

\section{Host-targeted Pan-respiratory Antiviral Therapeutics}

Figure $11 \mathrm{~A}$

\section{Uninfected cells}

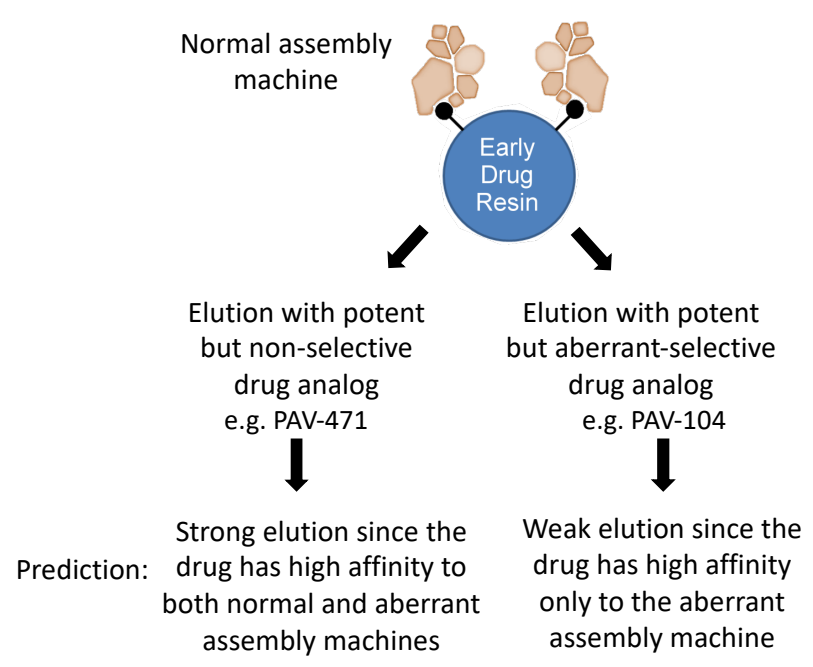

Infected cells

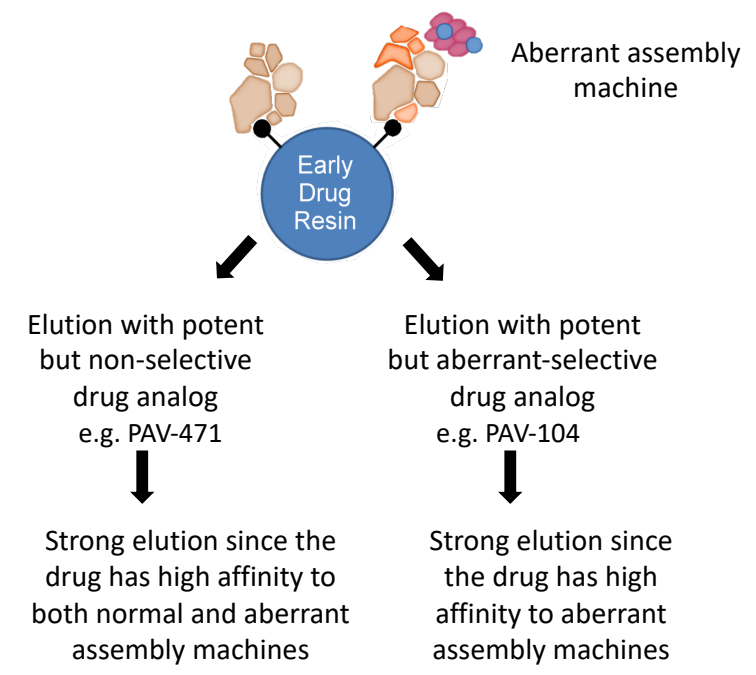

Figure 11B
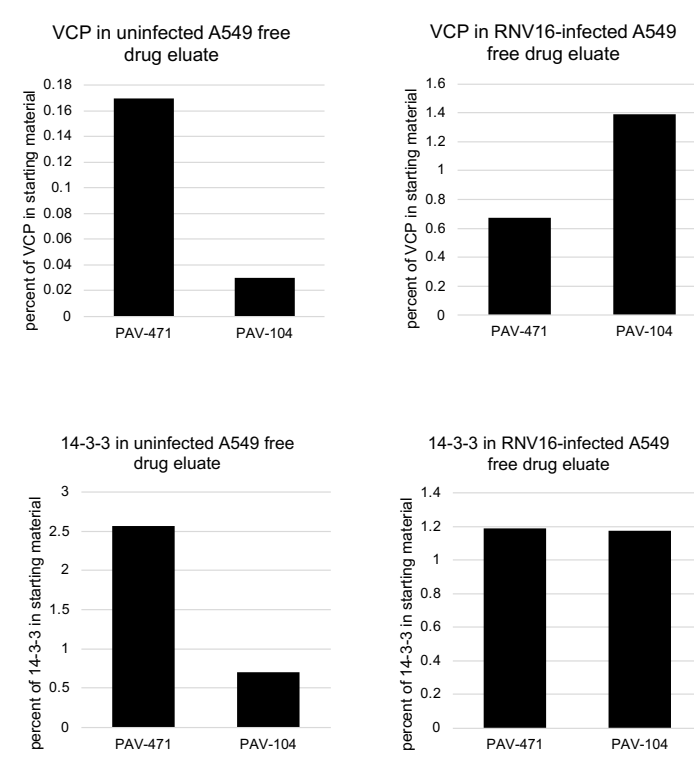

Figure 11. A. Prediction of outcome from uninfected vs infected extracts applied to an early non-selective drug resin and eluted with two advanced analogs, PAV-471 and PAV-104. Both advanced analogs show $>10 x$ greater anti-viral potency than PAV-431, but one is not aberrant assembly machine-selective and therefore shows toxicity in animals (PAV-471) vs the other (PAV-104) which is aberrant assembly machine-selective and shows $100 x$ less toxicity in animals. B. eDRAC outcome assessed by application of A549 cell extract before vs after infection with rhinovirus 16 to a PAV-431 drug resin followed by 100 bed volumes of wash and elution with either PAV-471 or PAV-104 and assessment of the free drug eluate by WB for a peripheral component (VCP/p97) and the direct drug-binding protein (14-3-3). Note that infected cells contain both normal and aberrant assembly machines perhaps because it is in the interest of the virus to keep the host alive and functioning sufficiently to support viral propagation. 


\section{Host-targeted Pan-respiratory Antiviral Therapeutics}

\section{Tables}<smiles>[R]c1cc(C(=O)N([R3])Cc2cc([R7])c([R6])c([R6])c2[R])n([R1])n1</smiles>

\begin{tabular}{|c|c|c|c|c|c|c|c|c|}
\hline compound & $\mathbf{R}_{1}$ & $\mathbf{R}_{\mathbf{2}}$ & $\mathbf{R}_{\mathbf{3}}$ & $\mathbf{R}_{\mathbf{4}}$ & $\mathbf{R}_{5}$ & $\mathbf{R}_{6}$ & $\mathbf{R}_{7}$ & $E C_{90}(\mu \mathrm{M})$ \\
\hline PAV-868 & $\mathrm{Me}$ & $\mathrm{t}-\mathrm{Bu}$ & $\mathrm{H}$ & OMe & OMe & $\mathrm{OMe}$ & $\mathrm{H}$ & $>3$ \\
\hline PAV-858 & $\mathrm{Me}$ & $\mathrm{t}-\mathrm{Bu}$ & $\mathrm{H}$ & OMe & $\mathrm{H}$ & $\mathrm{OMe}$ & $\mathrm{OMe}$ & $>3$ \\
\hline PAV-772 & $\mathrm{Me}$ & $\mathrm{t}-\mathrm{Bu}$ & $\mathrm{H}$ & OMe & $\mathrm{F}$ & $\mathrm{H}$ & $\mathrm{F}$ & 3 \\
\hline PAV-736 & $\mathrm{CH}_{2} \mathrm{CH}_{2} \mathrm{OH}$ & $\mathrm{t}-\mathrm{Bu}$ & $\mathrm{H}$ & OMe & $\mathrm{OMe}$ & $\mathrm{H}$ & $\mathrm{H}$ & $>3$ \\
\hline PAV-869 & $\mathrm{Me}$ & $\mathrm{t}-\mathrm{Bu}$ & $\mathrm{H}$ & $\mathrm{OPr}$ & OMe & $\mathrm{H}$ & $\mathrm{H}$ & $>3$ \\
\hline PAV-773 & $\mathrm{Me}$ & $\mathrm{t}-\mathrm{Bu}$ & $\mathrm{H}$ & OMe & OMe & $\mathrm{H}$ & $\mathrm{H}$ & 1.25 \\
\hline PAV-1866 & $\mathrm{Me}$ & $\mathrm{t}-\mathrm{Bu}$ & $\mathrm{Me}$ & OMe & OMe & $\mathrm{H}$ & $\mathrm{H}$ & $>3$ \\
\hline PAV-834 & $\mathrm{Me}$ & $\mathrm{Me}$ & $\mathrm{H}$ & OMe & OMe & $\mathrm{H}$ & $\mathrm{H}$ & 3 \\
\hline PAV-854 & $\mathrm{Me}$ & Cy-hex & $\mathrm{H}$ & OMe & OMe & $\mathrm{H}$ & $\mathrm{H}$ & $>1$ \\
\hline PAV-530 & $\mathrm{Me}$ & $\mathrm{iPr}$ & $\mathrm{H}$ & OMe & OMe & $\mathrm{H}$ & $\mathrm{H}$ & 1 \\
\hline PAV-835 & $\mathrm{Me}$ & cyPr & $\mathrm{H}$ & OMe & OMe & $\mathrm{H}$ & $\mathrm{H}$ & 1 \\
\hline
\end{tabular}

Table 1. Medicinal chemistry of early compounds resulting in identification of compounds PAV773 and PAV-835. Activity data shown is for FLUV. 


\section{Host-targeted Pan-respiratory Antiviral Therapeutics}

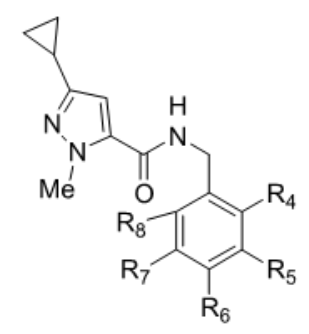

\begin{tabular}{|c|c|c|c|c|c|c|}
\hline compound & $\mathbf{R}_{\mathbf{4}}$ & $\mathbf{R}_{\mathbf{5}}$ & $\mathbf{R}_{\mathbf{6}}$ & $\mathbf{R}_{\mathbf{7}}$ & $\mathbf{R}_{\mathbf{8}}$ & $\mathbf{E C}_{90}(\boldsymbol{\mu M})$ \\
\hline PAV-895 & $\mathrm{OMe}$ & $\mathrm{Me}$ & $\mathrm{H}$ & $\mathrm{H}$ & $\mathrm{H}$ & 2 \\
\hline PAV-039 & $\mathrm{OMe}$ & $\mathrm{OMe}$ & $\mathrm{H}$ & $\mathrm{H}$ & $\mathrm{F}$ & 1 \\
\hline PAV-896 & $\mathrm{Me}$ & $\mathrm{OMe}$ & $\mathrm{H}$ & $\mathrm{H}$ & $\mathrm{H}$ & 1.5 \\
\hline PAV-700 & $\mathrm{Cl}$ & $\mathrm{OMe}$ & $\mathrm{H}$ & $\mathrm{H}$ & $\mathrm{H}$ & 2 \\
\hline PAV-235 & $\mathrm{F}$ & $\mathrm{OMe}$ & $\mathrm{H}$ & $\mathrm{H}$ & $\mathrm{H}$ & 0.2 \\
\hline PAV-944 & $\mathrm{OMe}$ & $\mathrm{CF}_{3}$ & $\mathrm{H}$ & $\mathrm{H}$ & $\mathrm{H}$ & 0.2 \\
\hline PAV-901 & $\mathrm{CF}_{3}$ & $\mathrm{OMe}$ & $\mathrm{H}$ & $\mathrm{H}$ & $\mathrm{H}$ & 0.3 \\
\hline PAV-671 & $\mathrm{H}$ & $\mathrm{Cl}$ & $\mathrm{OCF}$ & $\mathrm{H}$ & $\mathrm{H}$ & 0.05 \\
\hline PAV-774 & $\mathrm{Cl}_{3}$ & $\mathrm{OCF}_{3}$ & $\mathrm{H}$ & $\mathrm{H}$ & $\mathrm{H}$ & 0.2 \\
\hline PAV-431 & $\mathrm{OMe}$ & $\mathrm{OCF}_{3}$ & $\mathrm{H}$ & $\mathrm{H}$ & $\mathrm{H}$ & $<0.1$ \\
\hline PAV-528 & $\mathrm{OCHF}_{2}$ & $\mathrm{OCHF}_{2}$ & $\mathrm{H}$ & $\mathrm{H}$ & $\mathrm{H}$ & $<0.1$ \\
\hline PAV-877 & $\mathrm{H}$ & $\mathrm{Me}$ & $\mathrm{OCHF}_{2}$ & $\mathrm{Me}$ & $\mathrm{H}$ & $>2$ \\
\hline
\end{tabular}

Table 2. Early advanced compounds culminating in PAV-431 whose synthetic scheme is shown in Supplementary Figure 1. Activity data shown is for FLUV. 
bioRxiv preprint doi: https://doi.org/10.1101/2021.01.17.426875; this version posted December 13, 2021. The copyright holder for this preprint (which was not certified by peer review) is the author/funder, who has granted bioRxiv a license to display the preprint in perpetuity. It is made available under aCC-BY-NC-ND 4.0 International license.

\section{Host-targeted Pan-respiratory Antiviral Therapeutics}

\begin{tabular}{|c|c|c|}
\hline \multicolumn{2}{|c|}{} & Percent reduction in WSN33 Infection \\
\hline \multirow{2}{*}{ Oseltamivir } & Passage 0 at $30 \mathrm{mM}$ & 91 \\
\cline { 2 - 3 } & Passage 7 at $30 \mathrm{mM}$ & 21.4 \\
\hline \multirow{2}{*}{ PAV-835 } & Passage 0 at $3 \mathrm{mM}$ & 98.9 \\
\cline { 2 - 3 } & Passage 7 at $3 \mathrm{mM}$ & 91.9 \\
\hline \multirow{2}{*}{ PAV-333 } & Passage 0 at $3 \mathrm{mM}$ & 94.53 \\
\cline { 2 - 3 } & Passage 7 at $3 \mathrm{mM}$ & 92.46 \\
\hline
\end{tabular}

Table 3. Evidence for a barrier to resistance development. MDCK cells were infected with FLUV A/WSN/33 in the presence of increasing concentrations of either oseltamivir (935 nM to $30 \mu \mathrm{M})$, PAV-835 (93.5 nM to $3 \mu \mathrm{M})$, or PAV-333 (93.5 nM to $3 \mu \mathrm{M})$. Sensitivity of the drug naïve virus compared to virus after 7 passages over the indicated drug concentration range is shown. An initially oseltamivir-sensitive influenza strain became largely resistant after passage 7 . In contrast, the two assembly modulator compounds PAV-835 and PAV-333 show minimal loss of drug sensitivity. 